\title{
The Holocene paleo-environmental history of the Gangkou River estuary, Hengchun Peninsula, Taiwan
}

\author{
Christopher Lüthgens ${ }^{1, *}$, Lih-Der $\mathrm{Ho}^{2}$, Nikolaus Clemenz ${ }^{3}$, Jia-Hong Chen ${ }^{2}$, Chia-Hong Jen ${ }^{2}$, \\ Jiun-Yee Yen ${ }^{4}$, and Shyh-Jeng Chyi ${ }^{2}$ \\ ${ }^{1}$ Institute for Applied Geology, University of Natural Resources and Life Sciences, BOKU, Vienna, Austria \\ ${ }^{2}$ Department of Geography, National Kaohsiung Normal University, Kaohsiung City, Taiwan \\ ${ }^{3}$ Mott MacDonald - Global Engineering, Management and Development Consultants, Cambridge, United Kingdom \\ ${ }^{4}$ College of Environmental Studies, National Dong Hwa University, Hualien, Taiwan
}

\section{Article history: \\ Received 29 August 2017 \\ Revised 4 May 2018 \\ Accepted 7 May 2018 \\ Keywords:}

Taiwan, Hengchun Peninsula, Quartz and feldspar OSL dating, pIRIR150, Double-SAR, Paleo-environmental reconstruction, Geochronology, Eustatic sea-level, Uplift rate, Coastal development, Estuarine environment, Neotectonic development

Citation:

Lüthgens, C., L.-D. Ho, N. Clemenz, J.-H. Chen, C.-H. Jen, J.-Y. Yen, and S.-J. Chyi, 2018: The Holocene paleo-environmental history of the Gangkou River estuary, Hengchun Peninsula, Taiwan. Terr. Atmos. Ocean. Sci., 29, 547-576, doi:

10.3319/TAO.2018.05.07.01

\begin{abstract}
The Taiwan coastal areas are facing predicted sea-level rise effects in the global climate change context. Better understanding of the mechanisms and forcing factors driving the geomorphological evolution of Taiwan's coastline is essential. We highlight the potential of small river estuaries as archives of coastal evolution and provide a paleo-environmental reconstruction of the Gangkou River estuary based on results from a combined methodological approach using geomorphological, sedimentological, and geochronological analyses. A consistent chronology was established by combining Optically Stimulated Luminescence (OSL) dating, as well as radiocarbon dating techniques. A distinct beach-rock layer allowed firm correlation of six investigated coastal profiles. Eustatic sea level change was identified as the primary coastal and estuarine landscape development forcing factor in the study area. Tectonic forcing could also be detected from the investigated sites, but has to be regarded as a subordinate secondary forcing factor. The Gangkou River estuary developed in the early Holocene at about $8 \mathrm{ka}$ and was fully developed by the time the Holocene sea-level maximum was reached. With the sea-level dropping until modern times, estuarine zone relocation and a transition to terrestrial processes was initiated, leading to development of the current coastal dune system since about $2.5 \mathrm{ka}$. Major dune building phases correlate with the climate change associated with the Little Ice Age (LIA) event and stabilised towards recent times, which is in accordance with regional and over-regional coastal Aeolian records in Taiwan.
\end{abstract}

\section{INTRODUCTION}

Better understanding of the forcing factors driving coastal area geomorphological development, resulting in coastal progradation or coastline retreat, has become an important issue in the contemporary and projected sea-level rise context (Nicholls and Cazenave 2010; IPCC 2014; Carson et al. 2016). Based on modelling, Chen et al. (2018) calculated an expected sea level rise in the China Seas of $0.6-1.3 \mathrm{~m}$ in the 21 st century. This will cause coastline changes that will affect a broad portfolio of spheres, including, but not limited to: coastal hazard and risk assessment (e.g., Wainwright et al. 2015), spatial planning (e.g., Suroso

\footnotetext{
* Corresponding author

E-mail: christopher.luethgens@boku.ac.at
}

and Firman 2018), the economy (e.g., Nováčková and Tol 2018), nature conservation and biodiversity (e.g., Feagin et al. 2005; Courchamp et al. 2014), and organic carbon fluxes in coastal ecosystems (e.g., Carnero-Bravo et al. 2018). In these contexts, Wainwright et al. (2015) stressed the importance of including geomorphological history in modelling, assessing and projecting coastal development. However, reconstructing that geomorphological and paleo-environmental history may be challenging in itself, often starting with the limited availability and accessibility of suitable archives for analysis. In this study, we highlight the potential of small catchment areas and estuaries in Taiwan to overcome this issue. A combined geomorphological, geochronological and sedimentological approach is applied for Holocene 
paleo-environmental history reconstruction of the Gangkou River estuary, Hengchun Peninsula, southern Taiwan.

In general, coastal environments develop under the combined effects of terrestrial and marine processes. Geomorphological processes in these areas are therefore driven by multiple forcing factors like eustatic and/or relative sealevel rise and fall, sediment availability, tectonic uplift or subsidence, and climate change, to name but a few. Based on the landscape sensitivity concept of Brunsden and Thornes (1979), the landscape system reaction to a disturbance (changing forcing factor) is related to the system's resisting forces. With regard to different temporal and spatial scales, coastal environments and their related morphodynamics strive to adopt static, metastable or dynamic equilibrium states, all of which result in different types of stability, suggesting that such systems are resilient (Woodroffe 2007), i.e., able to recover to their initial equilibrium state as a response to system disturbance (Brunsden 2001). However, even if systems do recover, the recovery time may vary significantly, depending on the spatial scale of the system as a whole, or the magnitude of the impact (Pethick and Crooks 2000). Deciphering the complex geomorphological process network determining the resilience and vulnerability of such environments is a complex task. Forcing factors driving the environmental change must be identified and their changes over time must be reconstructed. In the chosen study area, the geomorphological landscape record and sedimentary archives provide valuable evidence of relevant processes. To capture the value of the information stored in these archives, establishing a reliable chronology of the recorded events is of central importance. Temporal correlation of different archives is best achieved by combining different numerical dating methods. From the broad portfolio of dating methods available today, radiocarbon and optically stimulated luminescence (OSL) dating have proven suitable tools in the research area and for the targeted time period (Ho et al. 2017).

In this study, we aim to reconstruct the paleo-environmental development of the Gangkou River estuary, southeastern Taiwan. This study identifies the phases of changing geomorphological forcing factor influence during the Holocene period resulting in system transition through different system states over time. The unique geomorphological and sedimentological records preserved in that area provide detailed information about both, the terrestrial and the marine regime, allowing a combined analysis of fluvial (terraces), coastal (beach and dunes), as well as shallow marine (estuarine and coral reefs) geomorphological and sedimentary archives. A prominent marker horizon of beach rock enables correlation of the outcrops situated on the coastline. Throughout the Holocene period, the Hengchun Peninsula has been situated in a subtropical environment typical for beach rock formation (Vousdoukas et al. 2007). For the paleo-environmental reconstruction, a detailed chronological framework will be established by applying numerical dating techniques. Landscape features and sedimentological successions were mapped in the field and samples were taken for high resolution grain size analyses, and for radiocarbon and optically stimulated luminescence (OSL) dating.

\section{RESEARCH AREA}

\subsection{Geological Background and Tectonic Setting}

Taiwan, an island with a high mountain range attaining nearly $4000 \mathrm{~m}$, is located in a unique position in East Asia, at the transition from the subtropical to the tropical zone. The climate is driven by the East-Asian monsoon, which is responsible for a humid climate during the whole year. In addition, earthquakes, tropical storms, and typhoons trigger intense morphodynamic processes (e.g., Dadson et al. 2003). Taiwan is located off the coast of southeastern China (Fig. 1a). The Taiwan arc-continent collision is the result of the oblique convergence of the Philippine Sea Plate and the Asian Continental Margin. The collision of the Luzon Arc on the Philippine Sea Plate with the Asian Continental Margin has led to the creation of the orogeny, which forms the island of Taiwan (Fig. 1b; Suppe 1980; Barrier and Angelier 1986; Teng 1990; Ramsey et al. 2006). The Philippine Sea Plate is moving north-northwest at a velocity of about $81.5 \mathrm{~mm}$ per year ( $\mathrm{Yu}$ et al. 1997). It is subducted under the Eurasian Plate at the Ryukyu trench in the North while along the Manila trench in the South the Eurasian plate is subducted beneath the Luzon Arc on the Philippine Sea plate. The collision in southern Taiwan set in at the end of the Miocene period (Pelletier and Stephan 1986). The emergence of central mountain belts and initial coupling with surface processes commenced at about $5 \mathrm{Ma}$ ago in northern Taiwan. It then propagated southward (Suppe 1984; Byrne and Liu 2002) with surface processes becoming effective in southern Taiwan about 3.5 Ma ago (Mesalles et al. 2014). Byrne and Liu's (2002) southward propagating model suggests that the Hengchun Peninsula (Fig. 1c) is the part of Taiwan that has emerged most recently. Chang et al. (2003) concluded that on the Hengchun Peninsula, four main stages of paleostress can be recognized based on brittle tectonics analysis, during which the Hengchun block underwent tilting and a $\sim 90^{\circ}$ clockwise rotation. The Hengchun Peninsula is composed of three main tectonostratigraphic units (Chang et al. 2003) (Fig. 1). The first unit consists of middle to late Miocene deep-marine turbidites forming the central part of the peninsula. These Mutan formation rocks include folded, generally non- or slightly metamorphic sandstones, siltstones and lenticular conglomeratic bodies. The second unit consists of Plio-Pleistocene shallow marine foreland sequences in the west, including the Maanshan formation and the Hengchun Limestone. These foreland sequences indicate an upward-shallow marine environment (Huang 1988). The third unit is the Kenting Mélange (Kenting formation), which forms the boundary between the first and second unit 


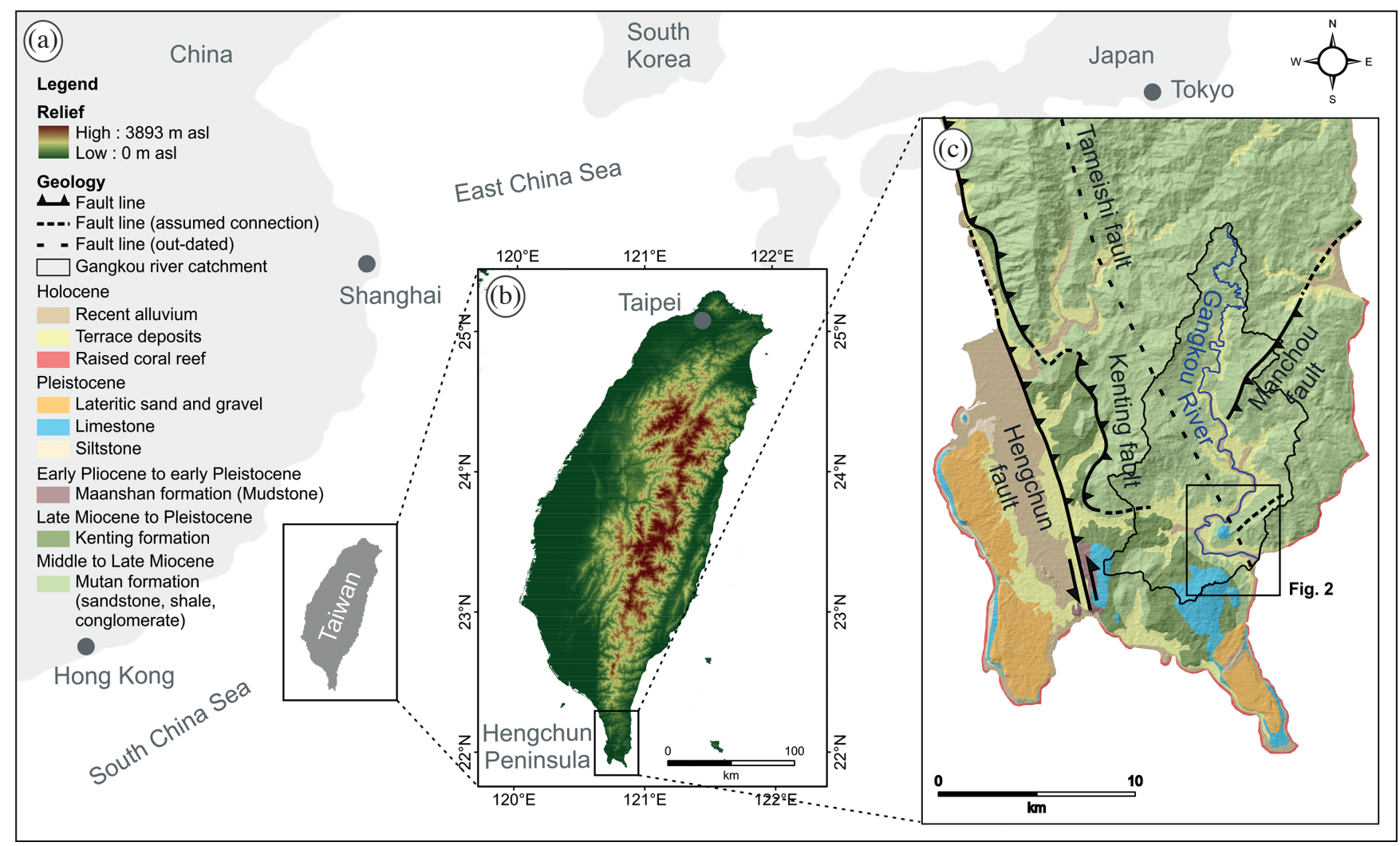

Fig. 1. (a) Overview map showing the location of Taiwan in an over-regional context. (b) Relief map of Taiwan showing the NNE-SSW trending ridges of the orogen and the location of the Hengchun Peninsula in the south of the island. (c) Map of the geology of the Hengchun Peninsula based on the geological map of the Hengchun Peninsula (Sung 1991). Tectonics adapted from Giletycz et al. (2015) and Zhang et al (2016). According to current knowledge, the Tameishi fault (shown in Sung 1991) is out-dated and assumed to be non-existent. It is only shown in this overview map for completeness and to illustrate the progress in research.

and is interpreted as a sheared and locally faulted tectonic mélange that developed from the late Miocene to the PlioPleistocene (Chang et al. 2003). Along the peninsula shoreline, the presence of raised coral reefs proves the general tectonic uplifting trend of the area (Fig. 1). Previous studies reconstructed uplift rates of around $3-4 \mathrm{~mm}_{\text {year }}{ }^{-1}$ during the Pleistocene and about $3.5 \mathrm{~mm}^{\text {year }}{ }^{-1}$ during the Holocene based on the radiocarbon ages of uplifted coral reefs (Cheng and Huang 1975; Liew and Lin 1987; Chen and Lee 1990; Wang and Burnett 1990; Chen and Liu 1993). VitaFinzi and Lin (2005) showed that uplift rates are higher in close proximity of the Hengchun fault and average about $2.5 \mathrm{~mm}$ year ${ }^{-1}$ for sites situated in larger distances from the fault. However, there is ongoing discussion about the fault mechanisms and activity dissecting the Hengchun Peninsula. While the official geological map (Sung 1991), as well as textbooks (Chen 2016) still present Hengchun Peninsula tectonics as dominated by a system of three thrustfaults (Manchou, Tameihsi, and Hengchun fault), recent discussions in scientific journals propose different tectonic models for the Hengchun Peninsula (e.g., Chang et al. 2003; Shyu et al. 2005; Huang et al. 2012; Zhang et al. 2014, 2016; Giletycz et al. 2015; Deffontaines et al. 2018).
Based on new observations presented in these studies, there is no convincing evidence for the existence of the Tameihsi fault, which is consequently not present in related tectonic models anymore (see Fig. 1c for the previously assumed course of the Thameihsi fault). Latest publications interpret the Kenting thrust-fold and the Hengchun transpressive strike-slip-fault to represent the outcropping top, or onshore contuinuation, of the offshore accretionary complex of the Hengchun ridge, which is part of the Manila accretionary prism (Huang et al. 2012; Zhang et al. 2014, 2016; Deffontaines at al. 2018). According to these most recent tectonic models for the Hengchun Peninsula, we do not expect active faults to occur in our study area (Figs. 1c and 2).

\subsection{Geomorphological Setting}

According to Giletycz et al. (2015), the Hengchun Peninsula landscape is in a transient stage resulting from a combination of rejuvenation and drainage arrangement caused by the late state of emergence of southern Taiwan. The study area is comprised of the lower reaches of today's Gangkou River catchment, situated in the southeastern part of the Hengchun Peninsula, and the costal landscape south 


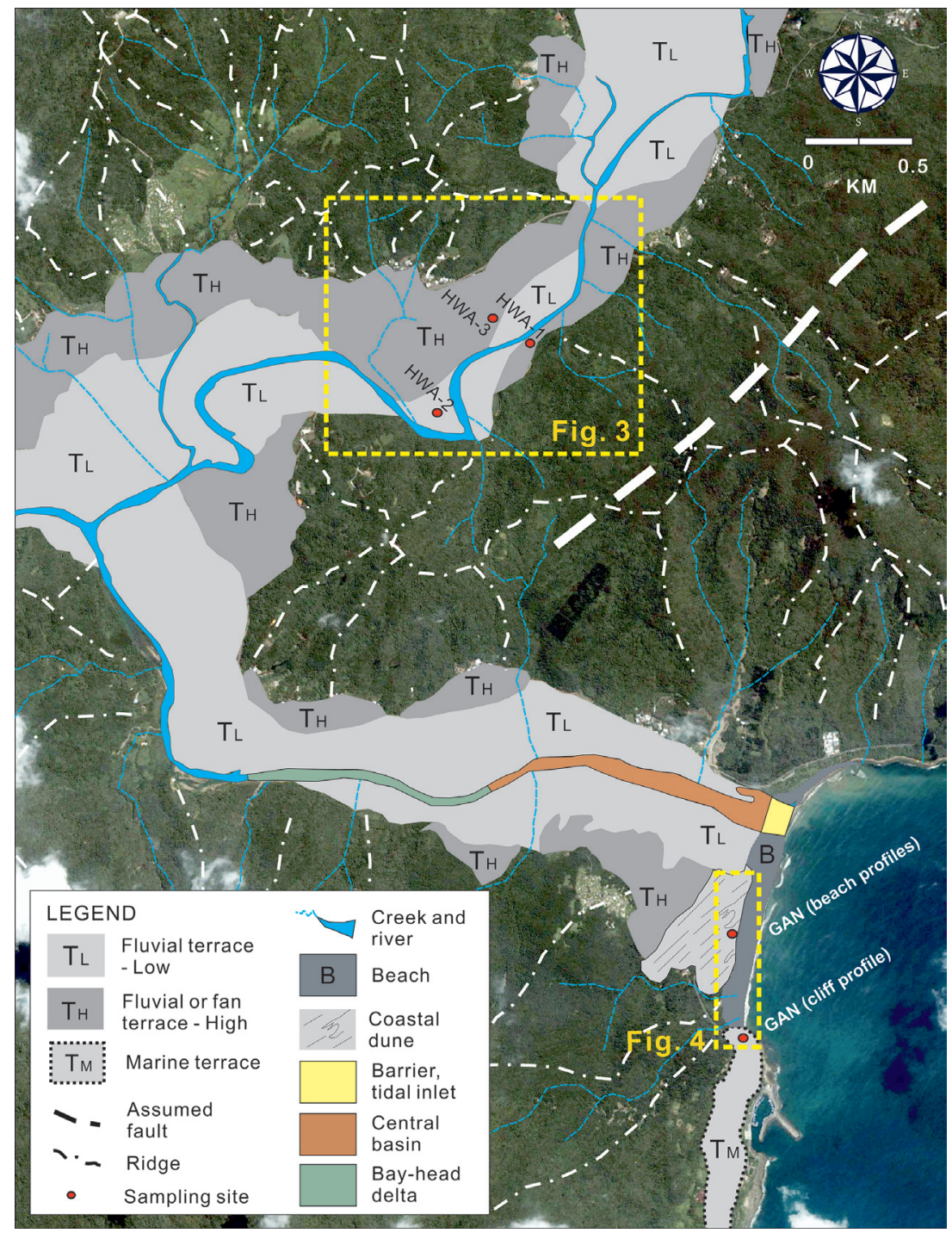

Fig. 2. Geomorphological map of the research area. The two sampling sites Hwa-Yuan (Fig. 3) and Gangkou beach and cliff (Fig. 4) are indicated. Within the lower reaches of the catchment, two terrace levels are present, whereas the higher terrace level $\left(\mathrm{T}_{\mathrm{H}}\right)$ is partly covered by sediments from alluvial fans originating from side valleys (details see Fig. 3). The main dune field south of the recent river mouth is shown, with the ridges oriented from NE to SW, following the dominant wind direction. Towards the south, the beach transitions to a cliff coast developed in raised coral reef (marine terrace $\mathrm{T}_{\mathrm{M}}$ ). Different colours indicate the zonation of the recent wave-dominated Gangkou River estuary: yellow - barrier and tidal inlet; brown - central basin; green - bay-head delta. Please note that under current conditions the river channel and estuary width are in large parts limited by artificial constructions (dams, concrete walls) for flood prevention.

of the recent river mouth (Figs. 1c and 2). The Gangkou River catchment area has a size of $102 \mathrm{~km}^{2}$ (Fig. 1c). The total drop in elevation of the modern channel over a length of $35 \mathrm{~km}$ is $425 \mathrm{~m}$, resulting in an average slope of $1.2 \%$. Significant amounts of fluvial deposits are present only in the middle and lower reaches, where the elevation drops a length of $27 \mathrm{~km}$ by $180.5 \mathrm{~m}$ and has a mean slope of $0.67 \%$. Knick points in the drainage system were documented in the higher catchment reaches (Giletycz et al. 2015), far upstream of the study area. The surrounding mountain ranges reach altitudes of about $600 \mathrm{~m}$. They are part of the southernmost extensions of the Central Mountain Range and consist mainly of Miocene sandstone and Mutan formation conglomerates.
The lower Gangkou River catchment reaches expose a pattern of two levels of fill terraces preserved in the valley bottom (Fig. 2). The higher terrace level $\left(\mathrm{T}_{\mathrm{H}}\right)$ is frequently covered and intercalated with alluvial fan sediments originating from side valleys (Figs. 2 and 3). The lower terrace level $\left(T_{L}\right)$ is frequently undercut by lateral fluvial erosion in the Gangkou River meander bends. The recent riverbed is characterised by numerous point bars. In the area around the Hwa-Yuan township (Fig. 3) the two terrace levels, as well as the point bars are nicely exposed and the sediments are accessible in different outcrops and provide a chance to reconstruct the timing of the latest sediment aggradation phases on these lowermost terrace levels (Figs. 2 and 3). 


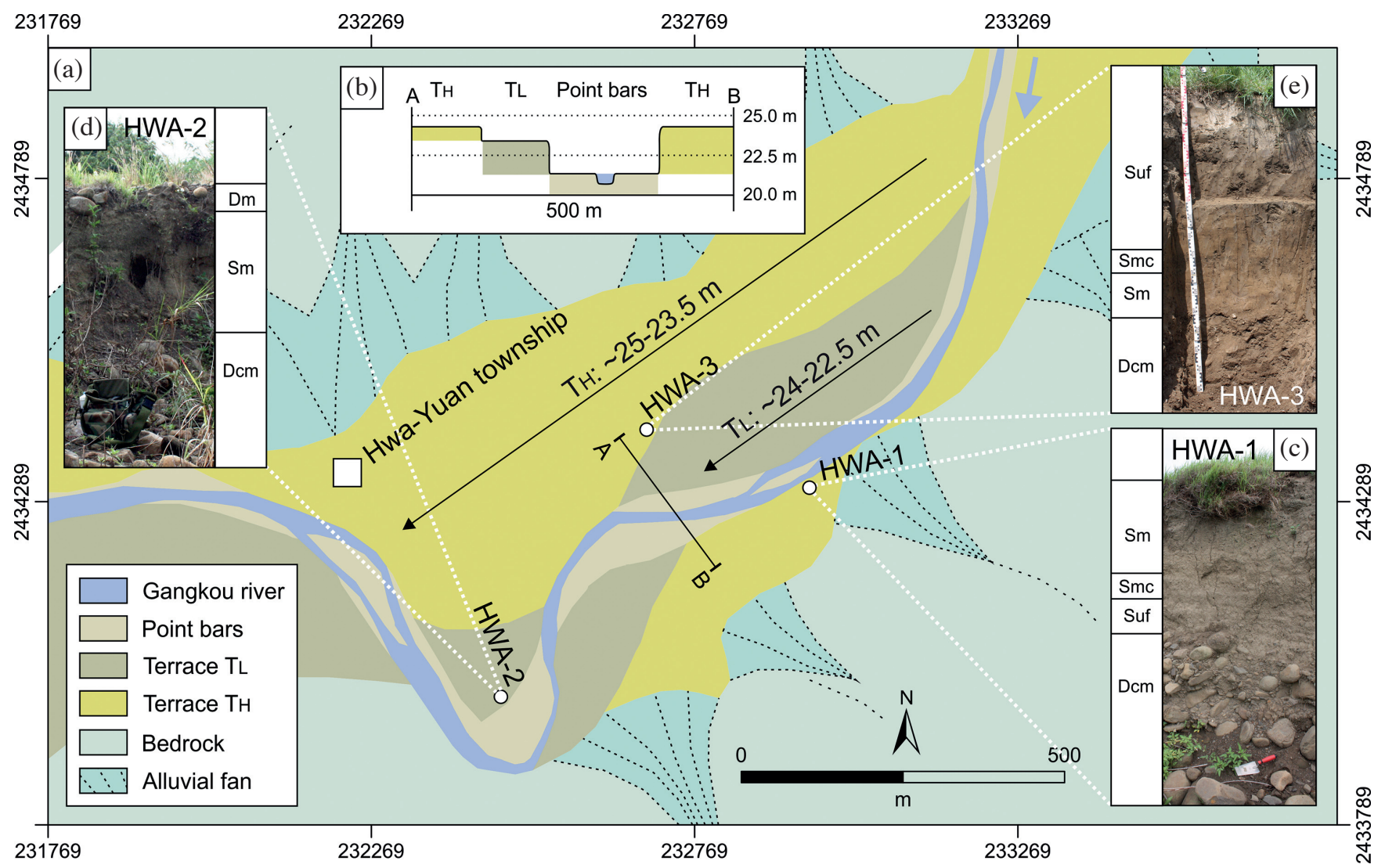

Fig. 3. (a) Detailed geomorphological map showing the area around Hwa-Yuan township and the three sampling sites in that area (for location see Fig. 2). Notable is the extremely sharp river bend of Gangkou River (general flow direction from East to West as indicated by blue arrow). Two terrace levels can be mapped, clearly separated from each other by scarps of approximately $1-2 \mathrm{~m}$. $\mathrm{T}_{\mathrm{L}}$ represents the lowermost terrace level, whereas $\mathrm{T}_{\mathrm{H}}$ represents the highest terrace level preserved around Hwa-Yuan. (b) Profile A - B across Gangkou River along the line marked in (a). (c) Photograph and facies codes of profile HWA-1. (d) Photograph and facies codes of profile HWA-2. (e) Photograph and facies codes of profile HWA-3. For sedimentological details concerning the sampled outcrops and for explanation of facies codes, please also see Fig. 10.

The area is located upstream of the recent Gangkou River estuary (Fig. 2). About $2 \mathrm{~km}$ downstream of the HwaYuan area, the Gangkou River enters its current estuary (Fig. 2). Following the definition of Dalrymple et al. (1992) for wave-dominated estuaries, it can be subdivided into three zones, the bay-head delta, the central basin, and the barrier/ tidal-inlet (Fig. 2). The landscape surrounding the estuary is characterised by intense agriculture today. The river channel and estuary width are in large parts limited by artificial constructions (dams, concrete walls) for flood prevention. The current river mouth is located in the northern part of the river valley. This has led to the preservation of older landscape units south of the river mouth, comprising coastal and fluvial landforms and sediments. The coastline north of the Gangkou River-mouth is characterized by a narrow sandy beach adjacent to the rocky mountain slopes (Fig. 2). The coastline south of today's river-mouth is characterized by a broad beach and landforms consisting of unconsolidated sediments (Figs. 2 and 4). The area is strongly influenced by the northeastern winter monsoon and by typhoons in the summer, because it is located on the eastern coast of the
Hengchun Peninsula. Since 1981, 11 typhoons have tracked through southernmost Taiwan from East to West, following the third most frequent typhoon pathway identified by Chang et al. (2018) based on data from the Typhoon Database of the Central Weather Bureau of Taiwan (http://rdc28.cwb. gov.tw/; date last accessed 2018.05.03). Long-term weather records show that northeasterly winds are dominant during winter, and can reach speeds as high as $10-17 \mathrm{~m} \mathrm{~s}^{-1}$ (Shih et al. 1994). This led to the build-up of up to $1.5 \mathrm{~km}$ long, 200 - $300 \mathrm{~m}$ wide dune ridges obliquely parallel to the coastline. Consequently, a relatively wide, sandy beach, accompanied by up to $10-20 \mathrm{~m}$ high coastal dunes stretches about $1.2 \mathrm{~km}$ south of the river-mouth. The shoreline characteristic changes again, as the beach transitions into a cliff coast. The coastal cliff outcrops show a comprehensive geological record: at the base, mid-Miocene bedrock is exposed, which is in part overlain by a thin layer of coral reef deposits, which transition into cemented beach deposits, partially overlain by dune sands (Fig. 4). Throughout the recent past, the sand dune bodies of Gangkou beach have experienced coastal erosion caused by high wave action in the course of typhoon 


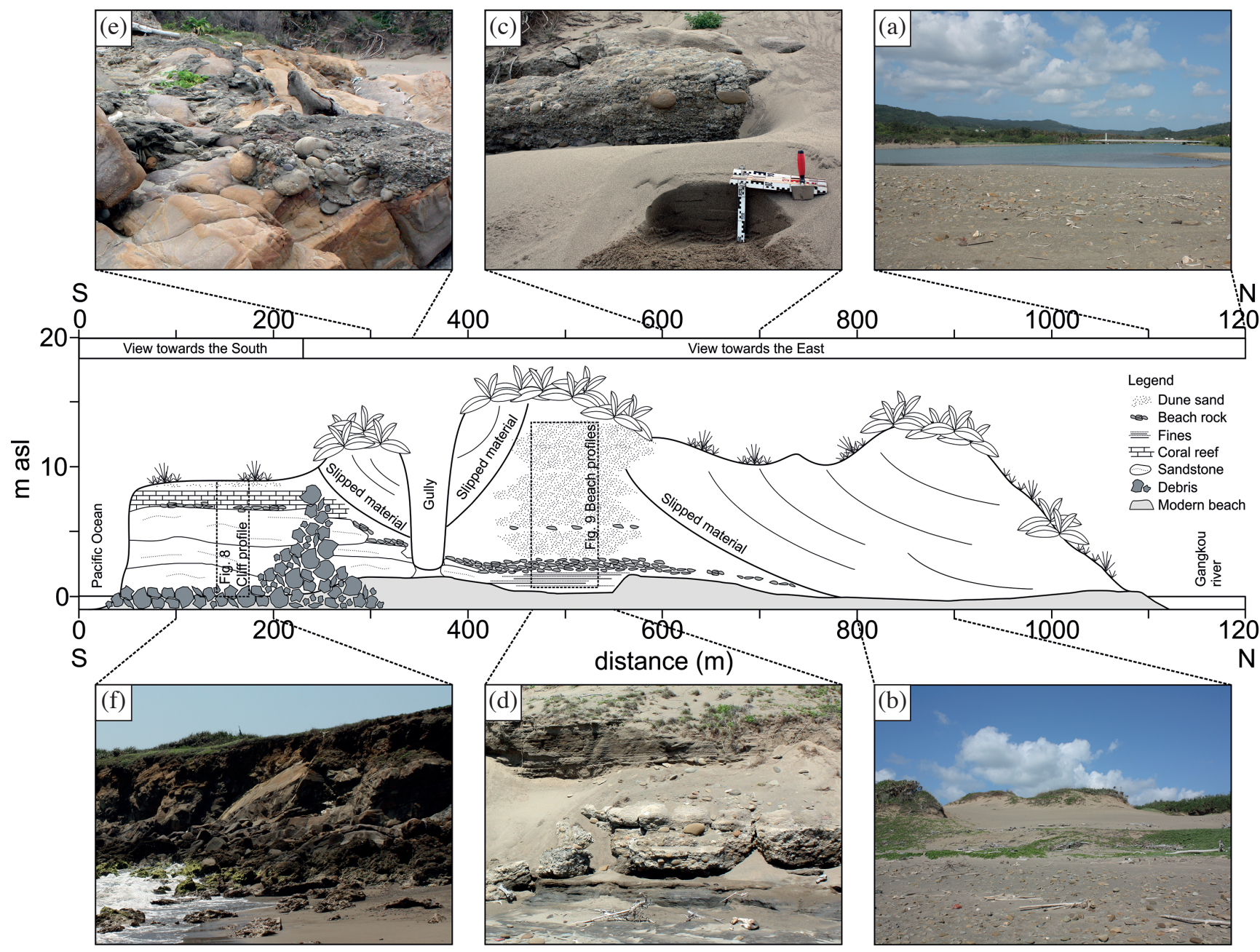

Fig. 4. Synoptic sketch and representative photos of the coastline from Gangkou River mouth southward to the cliff section. The whole beach area spans about $1.2 \mathrm{~km}$. In the northern part, accessibility to the sediments is limited, owing to material slipped off the slopes and freshly blown dune sand. The sketch illustrates the changing characteristics of the coast at Gangkou beach southward from the Gangkou River outlet. The sketch resembles the outcrop situation during the sampling campaign. The general view is towards the East. To fit the corresponding sections in the text, the figure and the photos should be viewed (read) from right to left. The dashed boxes in the sketch illustrate the location of the sampled sections. For details concerning the sampled profiles, please see Figs. 10 and 11. (a) View from the sand barrier to the East from Gangkou beach towards the river-mouth. Owing to low discharge, there was no surface connection between the river and the Pacific Ocean in spring 2014. (b) Recent beach sediments in the foreground and coastal dune ridges in the background. View from the beach to the East. Fresh sand, slipped material and vegetation covered this area and prevented accessibility of the sediments. (c) First occurrence of the beach rock at the base of the exposed section. Due to coastal erosion, blocks of the beach rock have broken off. The beach rock is covered by freshly blown sand of the same day, which was later sampled for OSL dating to provide a test sample with zero age. View from the beach to the East. (d) Central beach section before excavation showing the main sedimentary units: laminated fine sediments at the base, overlain by beach rock, topped by sandy beach and dune sediments. Thickness of the beach rock layer in the centre of the image about $1 \mathrm{~m}$. View from the beach to the East. (e) Patches of beach rock directly overlying the outcropping sandstone south of the gully. Diameter of the pebbles in the centre of the image is about $10 \mathrm{~cm}$. View from the beach to the East. (f) Cliff section showing the Miocene sandstone, beach rock, and coral reef carbonates topped by a minimal soil layer. View from the southernmost part of the beach to the South.

events. Therefore, the sediments are nicely exposed in the area and can be followed along several outcrops reaching up to $7 \mathrm{~m}$ in height, especially in the central and southern part of the beach (Fig. 4). The sedimentary succession accessible in these outcrops indicates a complex depositional history, probably encompassing the transition from a shallow marine depositional environment to a beach, and finally to a coastal Aeolian depositional environment.

\section{METHODOLOGY}

All outcrops under investigation were mapped in detail in the field (for locations see Fig. 2). Position and elevation data were carefully recorded to correlate the relative positions of all sites (GPS positions provided in Tables 1 and 2). Samples were taken for radiocarbon and OSL dating purposes from all sections. The coastal sediment outcrops were 


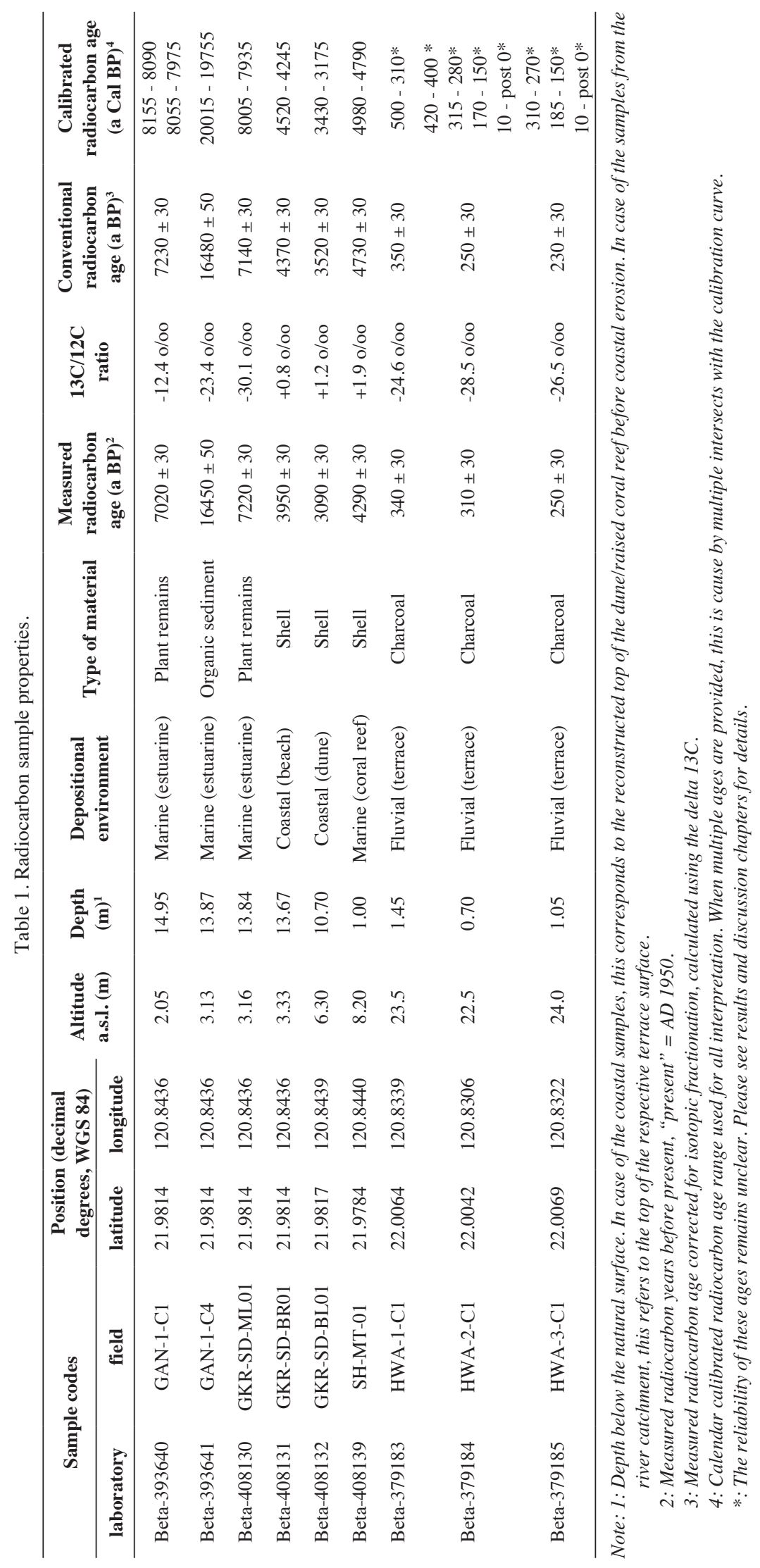




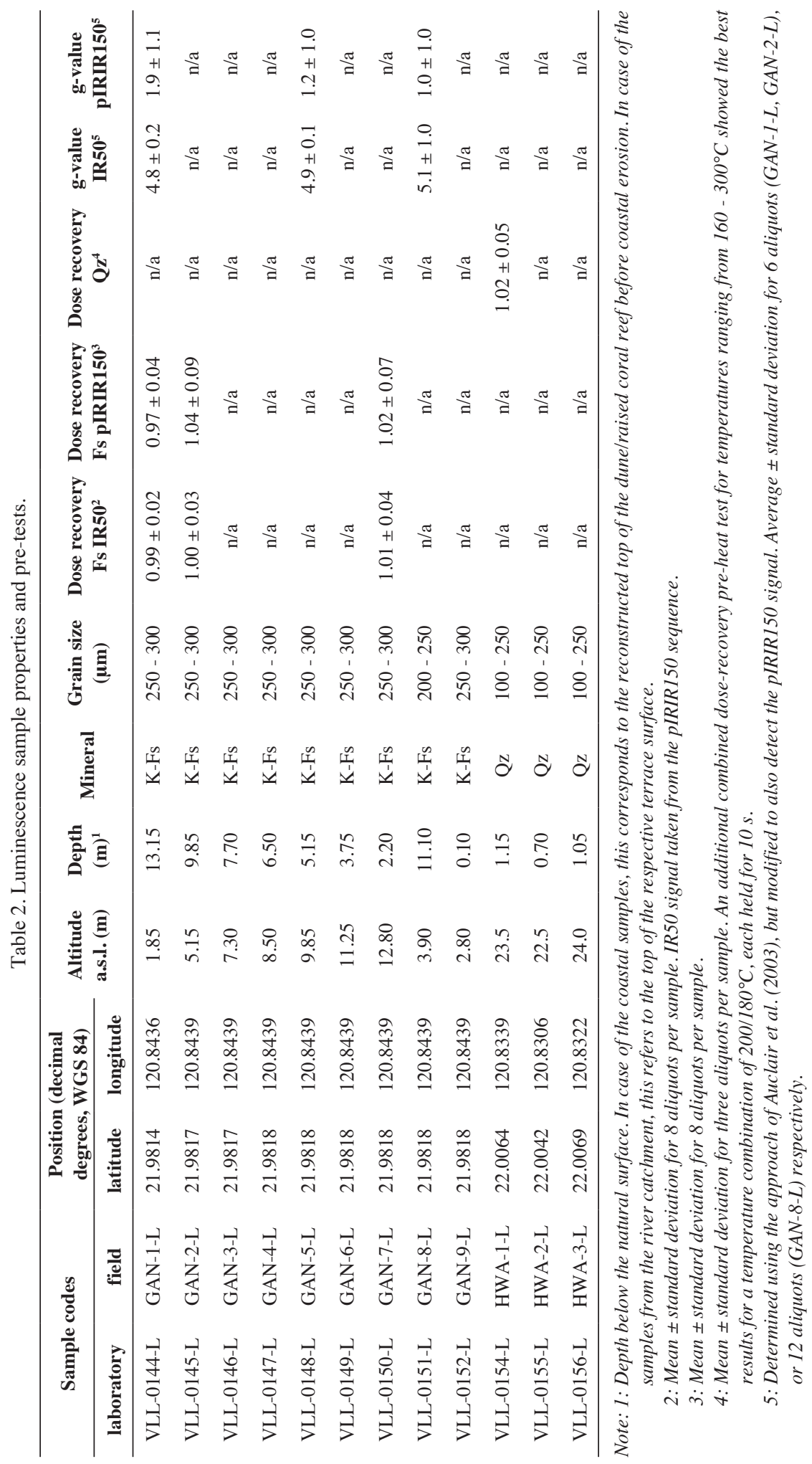


additionally sampled for high-resolution grain size analyses. Depending on the outcrop height, samples were collected every $5-30 \mathrm{~cm}$. In the following, we will give an overview of the sampled locations and provide a first characterization based on the initial field mapping to explain the sampling strategy. Additional detailed descriptions of the mapped sedimentary features, including layering and discontinuities, depositional structures, colour, and, if possible, other features such as fossil fragments and traces of bioturbation will be presented in the results section.

\subsection{Sampling Strategy}

A sampling strategy was developed to guarantee a representative selection of sites and depositional environments for Gangkou River estuary paleo-environmental reconstruction. Fluvial deposits were sampled in the Hwa-Yuan area. Figure 3 shows a geomorphological map of the Hwa-Yuan area and the three sampled sediment sections. At sites HWA-1 and HWA-2 natural outcrops caused by lateral fluvial erosion were accessible. At site HWA-3 an artificial outcrop was excavated for investigation. All three profiles are comprised of sediments forming the lowermost terrace levels of the Gangkou River. Profile HWA-1 is situated on the southeastern riverbank, where the Gangkou River recently actively undercut the terrace sediments. Profiles HWA- 2 and HWA-3 lie on the northwestern riverbank. The former is exposed in a natural outcrop in a sharp meander bend, while the latter is situated about $100 \mathrm{~m}$ distance from the recent riverbed at the terrace scarp separating $T_{L}$ and $\mathrm{T}_{\mathrm{H}}$ (Fig. 3). Although a natural outcrop was not available, a profile was excavated to enable sampling. The sedimentary structures were mapped in the field. Samples were taken for geochronological analyses. At all three sampling spots it was possible to obtain material for both radiocarbon and OSL dating (Tables 1 and 2).

Along the beach south of the river mouth it was possible to sample sediments from the shallow-marine, beach, and Aeolian depositional environments. Figure 4 shows a synoptic sketch of the coastline from the Gangkou River estuary southward to the beach termination and the cliff transition. The cliff consists of raised coral reef and underlying Miocene sandstone. It also shows the location of a gully incised down into the sandstone, which at that place forms the base of the beach outcrop. The sampled sections can be correlated by a layer of beach rock (Figs. $4 \mathrm{c}-\mathrm{f}$ ), that can be traced along the coastal reaches from the Gangkou River mouth right to the southern limits of Gangkou beach. Samples were collected from four outcrops in largely unconsolidated clastic sediments exposed along the eroding coastline (detailed photos of selected sampling spots see Fig. 5), and from the cliff forming the southern boundary of Gangkou beach (Fig. 4f). Five samples for radiocarbon dating were taken from the beach outcrops wherever suitable material was available. These samples included plant remains and shells (Fig. 5b, Table 1). To build a reliable chronology for the beach sections, an overall number of nine samples for OSL dating were taken from all sedimentary units, including the cemented beach rock (Fig. 5d) and a modern analogue from freshly blown Aeolian sand (Fig. 4c). The beach rock was sampled by carefully carving out a block of a cemented sand-rich layer using a hammer and chisel. The loose sediments could be sampled using steel cylinders. Following the coastline further south (Fig. 4) towards the incised gully, Miocene sandstone emerges at the base of the loose sediments. When crossing the gully to the south, the coast appearance changes to cliff. Aeolian cover sediments are only preserved further inland, west of the coastal road. They are not included in the analyses in this study. To determine the age of the coral reef section, a sample from a shell-rich layer was taken for radiocarbon dating. No suitable material was available for OSL dating there (Fig. 4f).

\subsection{Grain Size Analyses}

Grain size analyses were conducted using laser diffraction particle sizing and SediGraph analyses. The majority of samples (sandy coastal deposits) were analysed using a Microtrac S3500 laser diffraction particle size analyser at the geomorphological laboratory of National Kaohsiung Normal University (NKNU) geography department to determine the grain size distributions of particles $<2 \mathrm{~mm}$ in diameter in the samples. Each sample contained at least $200 \mathrm{~g}$ of material for the analysis. The sample preparation for grain size determination involves bulk sample drying $\left(104^{\circ} \mathrm{C}\right.$ for 24 hours) and a subsequent grain-size analysis pre-treatment (Lewis and McConchie 1994) to ensure minerogenic particle purity. The preparation process is described in detail in Ho et al. (2017). The measurements were repeated at least 3 times and the results were displayed in a standardized grain-size classification. Samples taken from fine sediments rich in silt and clay, and lacking larger proportions of sand were analysed using a Micromeritics SediGraph at the Department of Geodynamics and Sedimentology of the University of Vienna for grain size below $63 \mu \mathrm{m}$ analysis. Samples were first treated with $\sim 10 \% \mathrm{H}_{2} \mathrm{O}_{2}$ to dissolve organic matter and were then sieved at $63 \mu \mathrm{m}$ to insure that larger particles could not interfere with the analysis process. The dried sample material was then again dispersed in water for measurement. The results were displayed in a standardized grain size classification.

\subsection{Numerical Dating}

This study follows a combined methodological dating approach using complementary OSL and radiocarbon dating whenever suitable material was available from the sediment sections for both methods. Wherever available, individual 


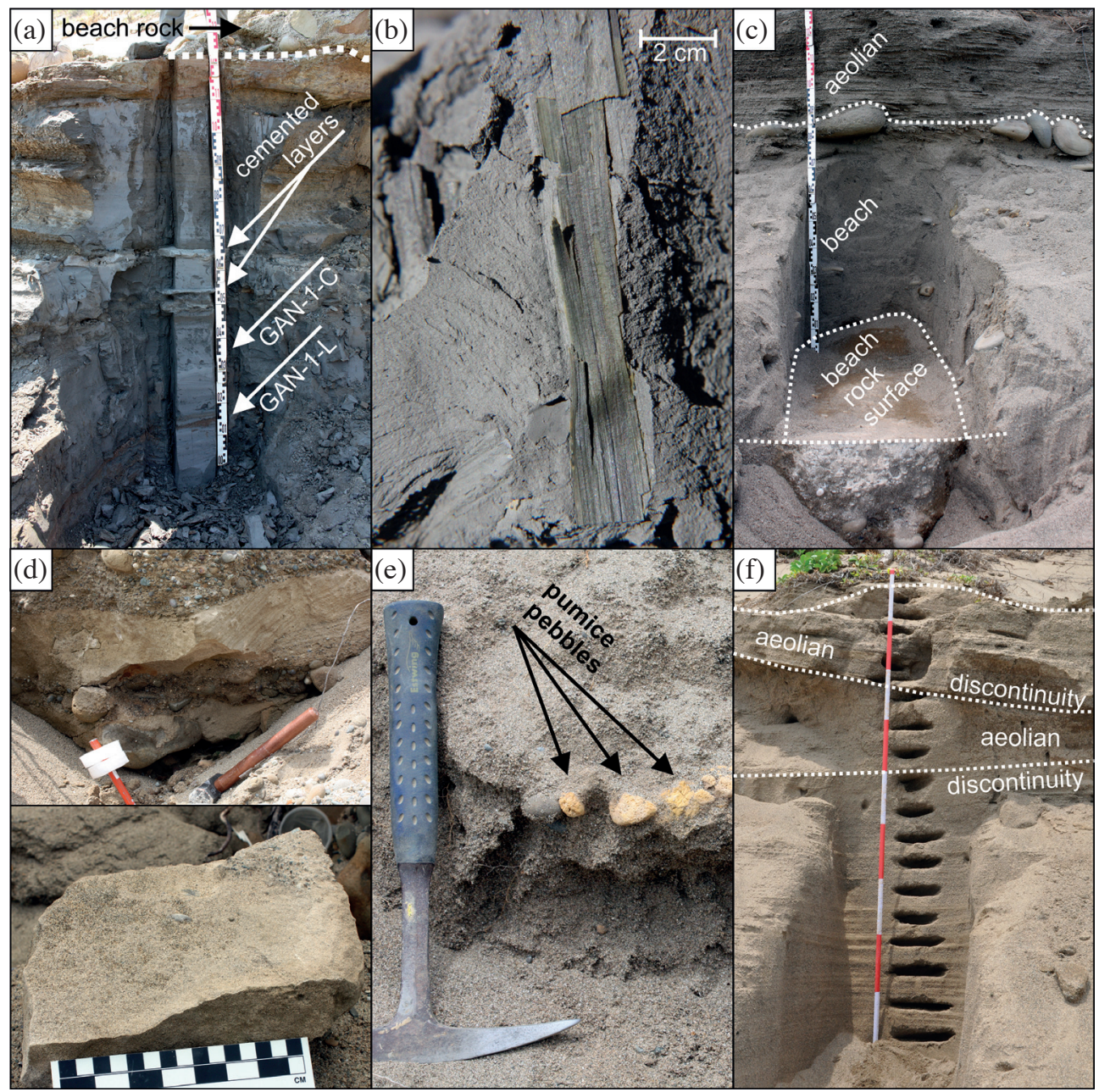

Fig. 5. Sampling details from the central beach section (location see Figs. 2 and 4). (a) Laminated silty/clayey sediments at the base of the section (stratigraphical Unit A). (b) Seaweed leafs from the lower part of the section displayed in subset (a). Similar material was sampled for radiocarbon dating (GAN-C-1). (c) Transition from beach rock (base) to unconsolidated beach sediments, to Aeolian sediments (section corresponding to stratigraphical Units B and C). (d) Beach rock sample for luminescence dating (GAN-8-L) before (top) and after (bottom) sampling. Length of the hammer in the top image about $20 \mathrm{~cm}$. The sampled sand lens shows clear cross-bedding features. The sampled block (bottom) measures approximately $20 \mathrm{~cm}$ in diameter. (e) Close up photo of a pumice-rich pebble layer (stratigraphical Unit C). (f) Topmost part of the central beach sections showing Aeolian sediments after sampling for grain-size analyses.

organic matter fragments (e.g., preserved leaves, pieces of charcoal, mollusc shells) were chosen for radiocarbon dating purposes. However, in the middle part of section GAN1 such fragments were missing, so that sample GAN-1-C4 was analysed using the bulk organic carbon content in the sample. All samples were handed to Beta Analytic for accelerator mass spectrometry (AMS) radiocarbon dating including calibration using databases associated with the 2013 INTCAL program. To ensure comparability with OSL ages, all radiocarbon ages are reported as calibrated before present (Cal BP) with the measured and the conventional radiocarbon ages (BP) provided as additional information in the results section only. All radiocarbon ages must be treated as maximum ages with respect to the sediment deposition they were incorporated in. Repeated redeposition of the material may even widen the gap between the obtained radiocarbon age (older) and the actually targeted depositional age (younger). Such offsets may be identified by independent age control, which was provided by OSL dating. Whereas radiocarbon dating provides an age for the death of an organism, OSL dating techniques in general enable the determination of the point in time when a sediment was last exposed to daylight during transport before deposition. Once buried and shielded from daylight, a latent luminescence signal starts building up by storing energy within the crystal lattice of quartz and feldspar minerals (known as the equivalent dose), originating from naturally occurring ionizing radiation (radioactive decay of ${ }^{40} \mathrm{~K}$, and the decay chains of ${ }^{235} \mathrm{U},{ }^{238} \mathrm{U}$, and ${ }^{232} \mathrm{Th}$, as well as cosmic radiation) over time (termed the dose rate). Once both, the equivalent dose and the dose rate, are known, the depositional age of a sample can be calculated using the general luminescence age equation: 
age (a) = equivalent dose $(\mathrm{Gy}) /$ dose rate $(\mathrm{Gy} / \mathrm{a})$

Further details on the OSL basic dating principles can be found in a number of review papers: Preusser et al. (2008), Wintle (2008), and Rhodes (2011).

Previous studies applying OSL dating techniques in Taiwan revealed that the luminescence properties of quartz are highly variable, with a variety of factors in some cases limiting the suitability for dating purposes. Major limitations are caused by overall dim luminescence signals, significant feldspar contamination and the presence of unfavourable signal components (Dörschner et al. 2012; Tseng et al. 2013, 2016). However, these studies also showed that despite these issues, reasonable results could be achieved using appropriate measurement protocols and careful data evaluation techniques. A study on a nearby dune section by Ho et al. (2017) recently showed that using potassium-rich feldspar as a dosimeter can serve as a valuable alternative to quartz, especially in environments that are not prone to incomplete bleaching (insufficient resetting of the luminescence signal during transport, leading to age overestimation if not detected and corrected for). For this study, both quartz and potassium-rich feldspar were used for dating. All samples were taken by driving steel cylinders into the freshly cleaned sediment face, with the exception of samples taken from the beach rock layer, which was sampled as a solid block of material. All analyses related to OSL dating were conducted at the Vienna Laboratory for Luminescence dating (VLL). Samples were prepared under subdued red light conditions according to standard procedures described in Lüthgens et al. (2017) and Rades et al. (2018). This included sample drying and sieving, leaching of carbonates $(10 \% \mathrm{HCl})$ and organics $\left(10 \% \mathrm{H}_{2} \mathrm{O}_{2}\right)$, density separation using LST FastFloat to obtain pure quartz and potassiumrich feldspar. Final quartz fraction etching (40\% HF) was conducted to remove the outer layer of material affected by alpha radiation.

\subsection{OSL Experimental Setup}

Samples for radionuclide determination using high resolution, low-level gamma spectrometry were first dried and then stored in sealed Marinelli beakers $(500 \mathrm{ml}$, each containing about $1 \mathrm{~kg}$ of dry weight sample material) for at least a month to establish secondary secular Rn equilibrium. All gamma spectrometry measurements were conducted at the VLL on a Canberra high purity Germanium (HPGe, 40\% n-type) detector. Samples were measured for 24 hours to achieve a desirable signal to noise ratio. The external dose rate was calculated using the resulting ${ }^{238} \mathrm{U}$, ${ }^{232} \mathrm{Th}$, and ${ }^{40} \mathrm{~K}$ contents (Table 3 ), by applying conversion factors of Adamiec and Aitken (1998) and the $\beta$-attenuation factors of Mejdahl (1979). Water content values were chosen to represent the average water content since burial and were adapted with respect to the grain size composition of each sample (Table 3). For internal K-feldspar dose rate calulation, an internal $\mathrm{K}$ content of $12.5 \pm 0.5 \%$ (following Huntley and Baril 1997) and an alpha efficiency (a-value) of $0.08 \pm 0.01 \%$ was used for all samples. The cosmic dose rate was calculated including geographical position, altitude, thickness and sediment overburden density effects following Prescott and Stephan (1982) and Prescott and Hutton (1994). Please see Table 3 for the details concerning dose rate calculation.

All luminescence measurements were carried out in the VLL on two RIS $\varnothing$ DA-20 luminescence reader systems (Bøtter-Jensen et al. 2000, 2003; Thomsen et al. 2006), both equipped with an internal beta source $\left({ }^{90} \mathrm{Y} /{ }^{90} \mathrm{Sr}\right)$ delivering a dose rate of approximately $0.1 \mathrm{~Gy} \mathrm{~s}^{-1}$. The luminescence quartz signal was stimulated using blue $(470 \mathrm{~nm})$ LEDs and detected in the ultraviolet spectrum (UV) using a Hoya U340 $(7.5 \mathrm{~mm})$ filter. The feldspar luminescence signal was stimulated using infrared $(870 \mathrm{~nm})$ LEDs and detected through a LOT Oriel $410 \mathrm{~nm}$ interference filter. As already expected from the results from a previous study (Ho et al. 2017), quartz turned out to be a questionable dosimeter for the samples from the coastal sections. Given the expected good bleaching conditions of this depositional environment, we refrained from using quartz as a dosimeter here, but used potassium-rich feldspar instead. A post infrared, infrared stimulated single aliquot regenerative dose protocol using a stimulation temperature of $150^{\circ} \mathrm{C}$ (pIRIR150 SAR protocol; Reimann and Tsukamoto 2012) already successfully applied in nearby dune sediments (Ho et al. 2017) was also tested for application in this study. After adding an additional clean out step after each SAR cycle (IR stimulation at $200^{\circ} \mathrm{C}$ for $200 \mathrm{~s}$ ), results from dose recovery experiments confirmed the suitability of the measurement protocol for both detected signals [pIRIR150, and IR50 (conventional IR signal at $50^{\circ} \mathrm{C}$ ), Fig. 6, Table 2]. Aliquots with $1 \mathrm{~mm}$ diameter (grain size 250 - $300 \mu \mathrm{m}$, about 10 grains on each aliquot) were used for all feldspar luminescence measurements. Fading experiments were conducted using the approach of Auclair et al. (2003), but modified to also detect the pIRIR150 signal.

Contrary to the coastal samples, quartz could be used as a dosimeter for samples taken from a fluvial depositional environment. Initial tests revealed the presence of a fast component, which is inevitable for dating, and which had been lacking in the quartz from the coastal samples (Fig. 7). Because feldspar contamination is detected independently from additional purification steps in the sample preparation, a post-infrared OSL SAR protocol (double-SAR, Banerjee et al. 2001; Roberts 2007) was tested. This yielded satisfactory results in the necessary pre-tests (Table 2). All quartz measurements were therefore conducted using this protocol. Due to the small bulk sample material grain size, the scarcity of coarse grained quartz, and the relatively dim signals, aliquots 


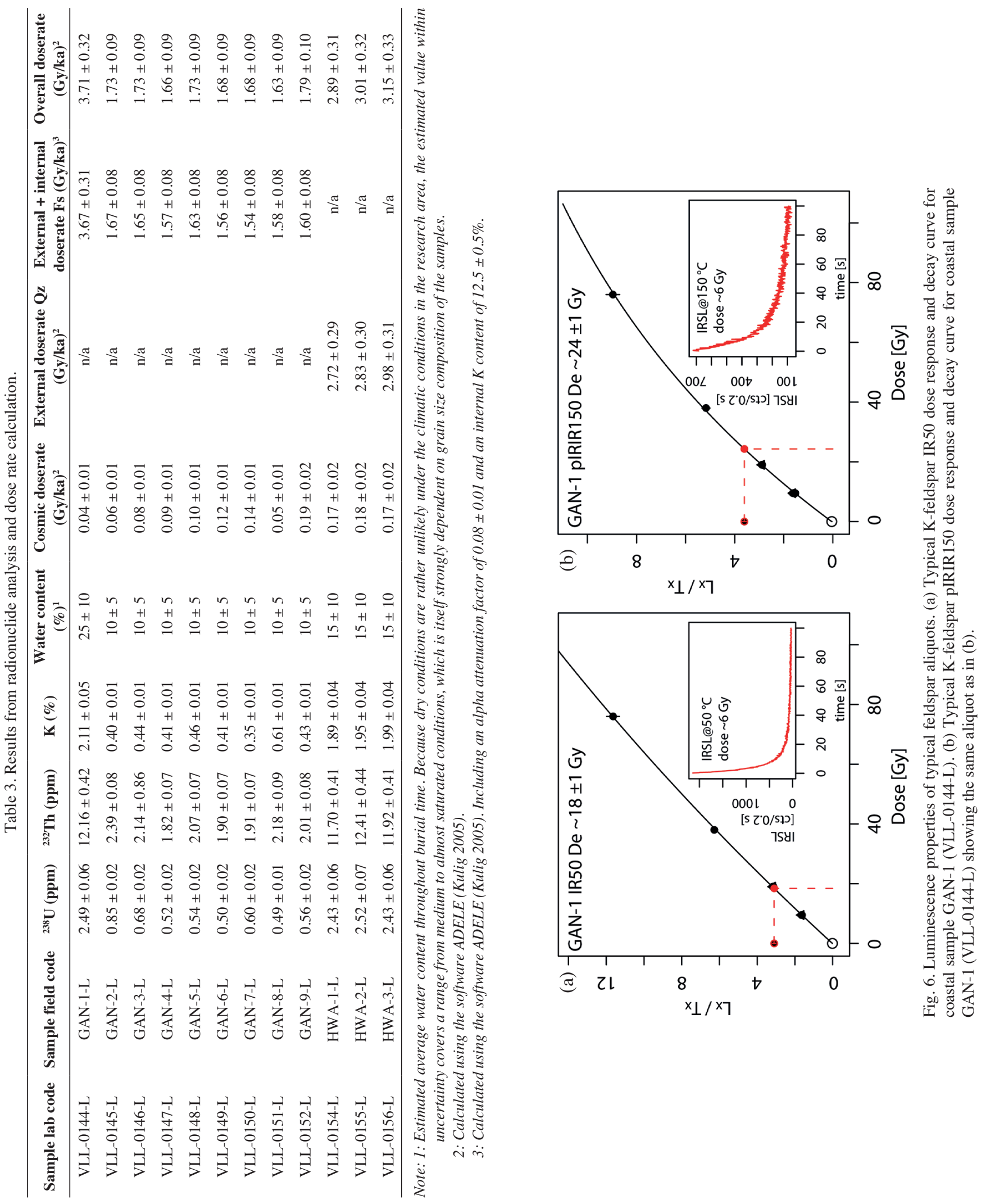



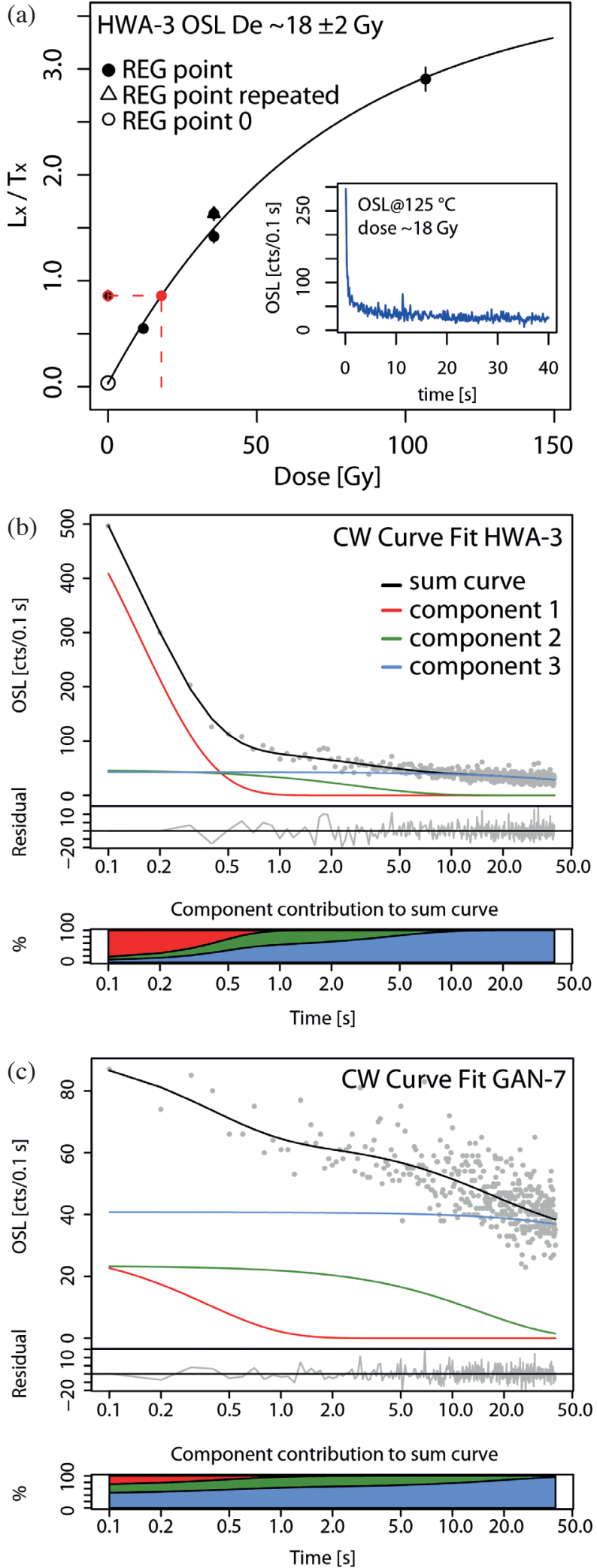

Fig. 7. Luminescence properties of typical quartz aliquots. (a) Typical quartz $\operatorname{OSL}\left(125^{\circ} \mathrm{C}\right)$ dose response and decay curve for fluvial sample HWA-3 (VLL-0156-L). (b) Component composition of the quartz continuous wave OSL signal of fluvial sample HWA-3 (VLL-0156-L) with a dominant fast component. (c) Component composition of the quartz continuous wave OSL signal of coastal sample GAN-7 (VLL0150-L) lacking a dominant fast component. with $2 \mathrm{~mm}$ diameter each containing about 80 grains in the grain size fraction of $100-250 \mu \mathrm{m}$ had to be used. However, tests on single grains of quartz revealed, that only about $3 \%$ of the grains emit significant luminescence signals. Therefore, averaging effects were expected to be minimal, not significantly shifting the equivalent dose to higher values even in the presence of incomplete bleaching, which is vital for the dating of fluvial samples. For the SAR protocol (Murray and Wintle 2000, 2003; Wintle and Murray 2006), a preheat combination of $200 / 180^{\circ} \mathrm{C}$, each held for $10 \mathrm{~s}$, was chosen based on the best performance at this temperature combination in the conducted pre-tests (Table 2).

\section{RESULTS}

\subsection{Gangkou River Terraces Around Hwa-Yuan}

The three profiles investigated in the Hwa-Yuan area all show similar stratigraphical patterns (Fig. 8). The base of the profiles is formed by coarse sediment layers (gravel, stones, and blocks), indicating high energy flow during deposition. Fine sediments (sand and silt) containing only isolated clasts of coarser material overlie these sediments. In one profile (HWA-2), a coarse layer similar to the base layer again overlies the fines. The base of profile HWA-1 is formed by a clast-supported diamicton, predominantly consisting of stones and boulders, with a silty to sandy matrix. In some parts of the outcrop wall, there are indications for channels cut into the coarse diamicton, which were subsequently filled with fine sediments. The upper part of the profile consists of fine, silty sand, only intercalated by a single coarser layer containing medium sand and some pebbles in a depth of $67-70 \mathrm{~cm}$ below surface. The second sampling spot HWA-2 exposes a very similar pattern as the one previously described. The main difference is that the profile is overlain by a clast- to matrix-supported diamicton, which shows smaller coarse clast grain sizes than the diamicton at the base of the profile (Fig. 8). The bedding structures clearly indicate sediment deposition as a natural fluvial deposit, but it also contains isolated clasts of concrete, pointing towards a more or less recent depositional age of that layer. At the base, profile HWA-3 (Fig. 8) also contains coarse material, mainly consisting of gravel and stones with a sandy to silty matrix. The top of the profile consists of fine silty sand, only intercalated by a layer of coarse silty sand with some pebbles at a depth of about $95-100 \mathrm{~cm}$ below surface. The sedimentary succession is very similar to that of profile HWA-1, which is situated on the opposite riverbank on the same terrace level $\mathrm{T}_{\mathrm{H}}$ (Fig. 3).

The results from radiocarbon dating are summarised in Table 1. Sample HWA-1-C1 yielded an age of 500 - $310 \mathrm{Cal}$ BP. Unfortunately, the two samples from sections HWA2 and HWA-3 did not yield unambiguous results, because of multiple intersects of the conventional radiocarbon ages with the calibration curve. Sample HWA-2-C1 yielded four 


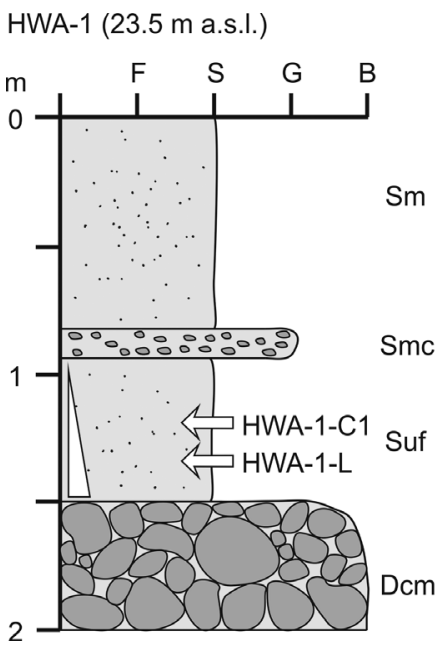

HWA-2 (22.5 m a.s.I.)

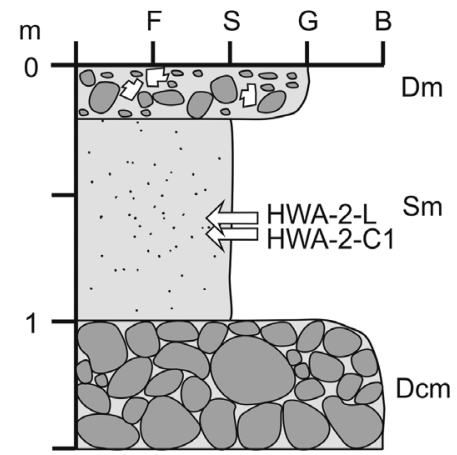

HWA-3 (24.0 m a.s.I.)

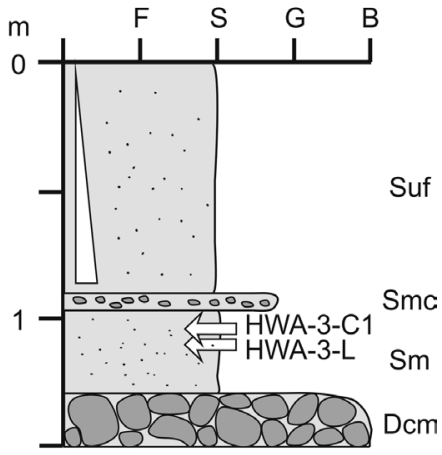

Fig. 8. Lithostratigraphical profiles of sites HWA-1, HWA-2, and HWA-3. Arrows indicate sampling spots for OSL and radiocarbon dating. Facies codes modified from Miall (1985): Dcm - Clast-supported diamicton; Dm - Matrix-supported diamicton; Sm - Massive sand; Smc - Massive sand with isolated outsized gravel clasts; Suf - Sand fining upward. Please note that the upper diamicton in profile HWA-2 contains clasts of concrete.

possible ages: 420 - 400, 315 - 280, 170 - 150, and 10-post 0 Cal BP. Calibration of sample HWA-3-C1 resulted in three possible age ranges: 310 - 270, 185 - 150, 10-post 0 Cal BP. Taking only the oldest possible age ranges into account, the ages for all three samples overlap within the error on the 2-sigma level. However, two of the samples also yielded possible recent ages postdating the radiocarbon zero year. In addition to the radiocarbon samples, three samples were dated using quartz OSL dating. Based on the results from dose recovery experiments, the following rejection criteria were defined: recycling ratio $<15 \%$, recuperation in percent of the natural signal $<15 \%$ and maximum test dose error $<$ $20 \%$. The signal was integrated over the first $0.5 \mathrm{~s}$, with the $1.3 \mathrm{~s}$ directly following the integration interval subtracted as background [early background subtraction cf. Cunningham and Wallinga (2010)]. After application of these criteria, 28 - 47 aliquots remained for data evaluation for each sample. The resulting equivalent dose distributions for samples HWA-1-L and HWA-2-L are positively skewed (Fig. 9), whereas HWA-3-L is normally distributed, but very broad, spanning an interval from about 5 - 60 Gy. Taking the overdispersion parameter as a measure of scatter (calculated using the Central Age Model, CAM, Galbraith et al. 1999) into account, all three samples show high values averaging about $80 \%$. These characteristics likely indicate that incomplete bleaching prior to deposition had a significant effect on the samples and the detected signals (Wallinga 2002; Bailey and Arnold 2006; Lüthgens et al. 2011). Considering this effect, the three-parameter Minimum Age Model (MAM, Galbraith et al. 1999) was applied for the calculation of an average equivalent dose value to be used in age calculation. For MAM calculations, the definition of a threshold value for the $\sigma_{b}$ parameter, defining the minimum expected scatter in the dataset expressed as an overdispersion value, must be determined. This can be done by adopting the overdispersionvalue calculated for well-bleached samples from the same environment. Unfortunately, a well-bleached sample was not available, so that the bootstrapped version of the MAM (Cunningham and Wallinga 2012) was applied, using a threshold value of 0.15 for $\sigma_{b}$ assigned with an uncertainty of 0.1 . The resulting equivalent doses were used for age calculation (Table 4). The ages for HWA-1-L ( $3.0 \pm 0.4 \mathrm{ka})$ and HWA-2-L ( $2.9 \pm 0.4 \mathrm{ka})$ agree within error, whereas sample HWA-2-L yields a significantly younger age of $0.5 \pm 0.1 \mathrm{ka}$. All OSL dating results are summarised in Table 4.

\subsection{Gangkou Beach and Cliff}

The sedimentology and geomorphology along Gangkou beach was mapped from the Gangkou River mouth southward to the cliff section, covering an overall distance of about $1.2 \mathrm{~km}$ (Figs. 2 and 4). Two sites were chosen for closer investigation and sampling, one in the central part of the beach, and one in the southernmost part of the beach (GAN beach profiles and GAN cliff profile, locations see Fig. 2). Both sites can be correlated by following a layer of beach rock functioning as a marker horizon. As summarised in the synoptic lithological profile of the central beach sampling site (Fig. 10), the sediment succession exposed here can be subdivided into four sub-sections. The basal part consists of laminated fine sediments (Unit A, silt and clay with some very fine sand, Fig. 5a), which are overlain by a layer of beach rock (unit B, Fig. 5a) developed in the form of a carbonate-cemented conglomerate containing wellrounded rocks and isolated sand lenses containing layered medium sands. Above the beach rock lie alternating layers of sands and gravels (Unit C), including a distinct sand layer with high amounts of pumice pebbles (Fig. 5e), and 


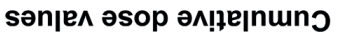
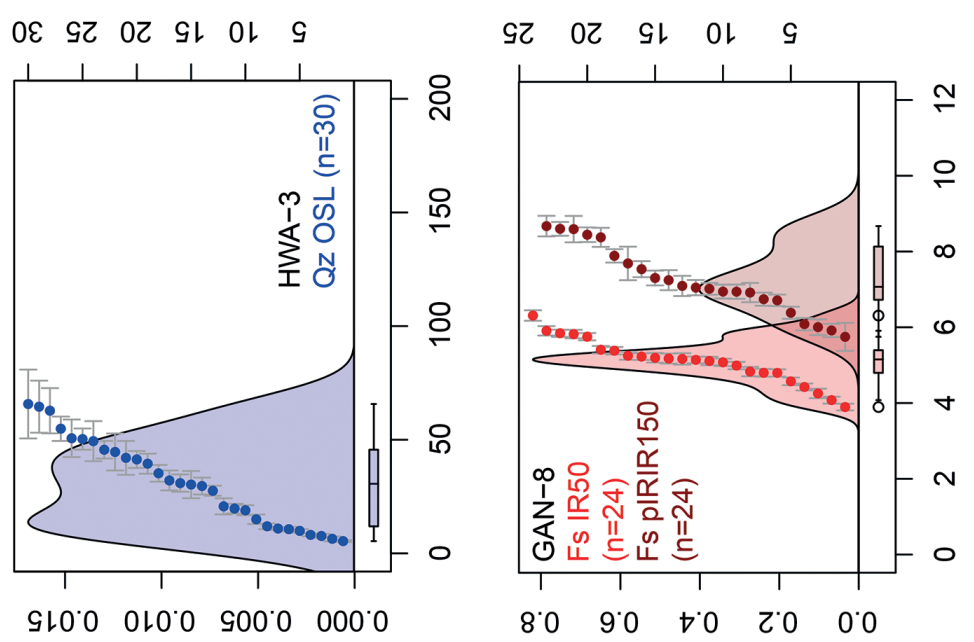

它

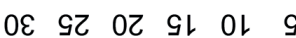

GZ OZ Gl OL $G$
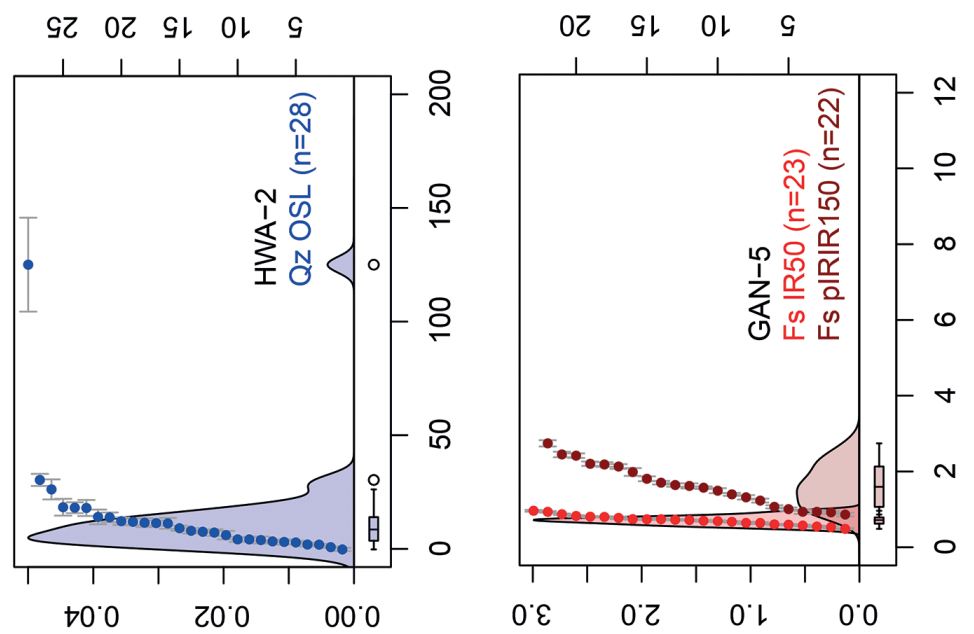

$\stackrel{0}{9}$

苞

:

药 类

政

츠 은

를

음

$\because$

吾泉

绐

$\Xi$ 路

沓

글

陨
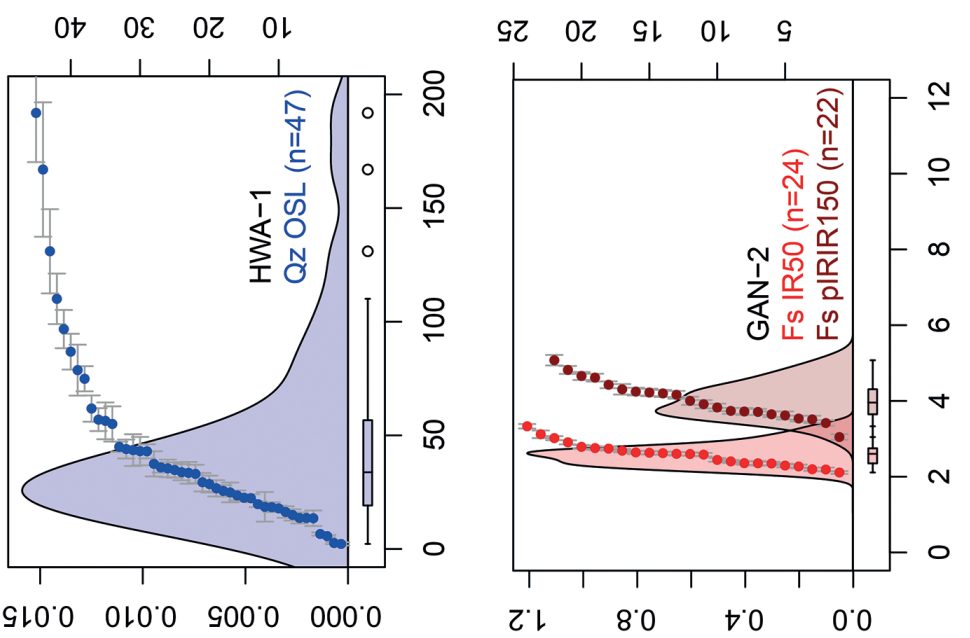

告

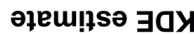

脑 


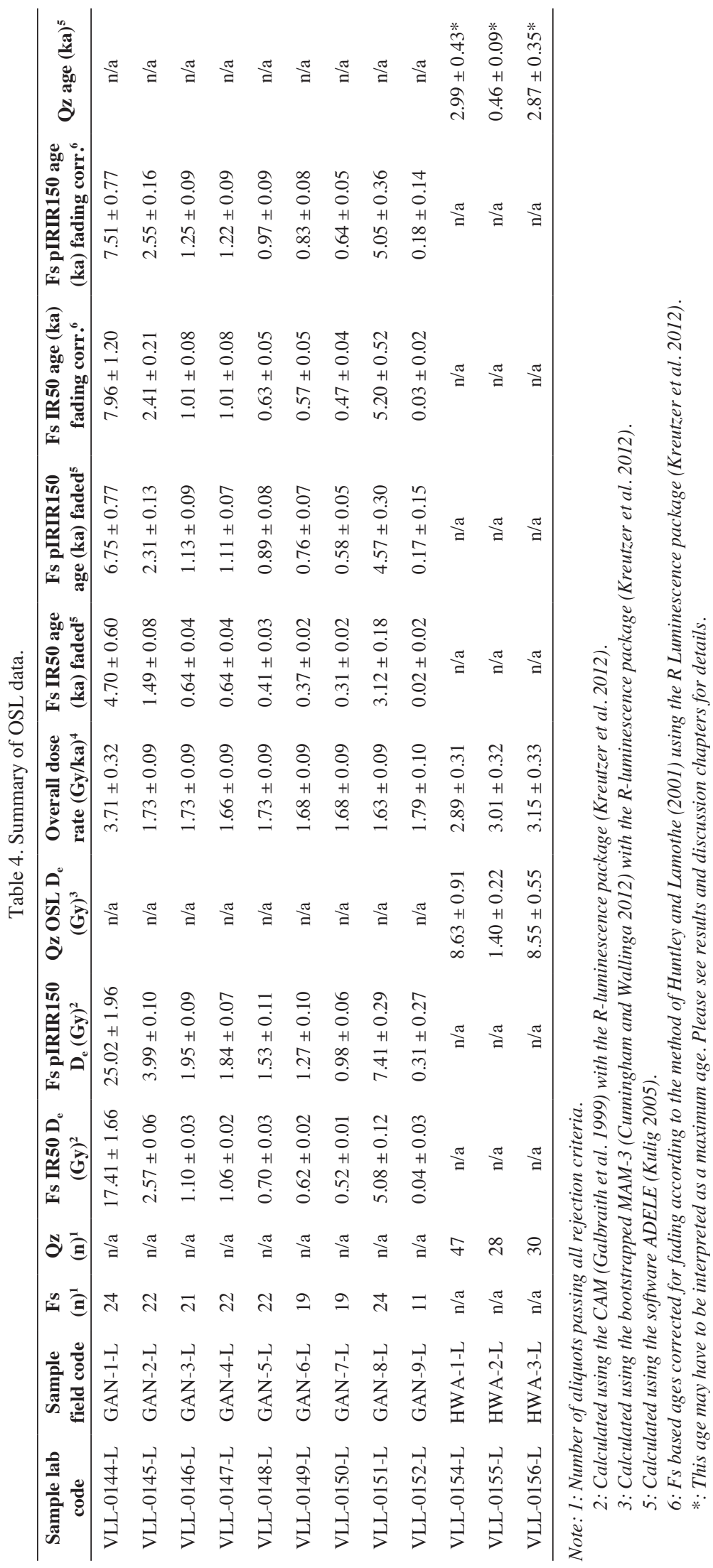




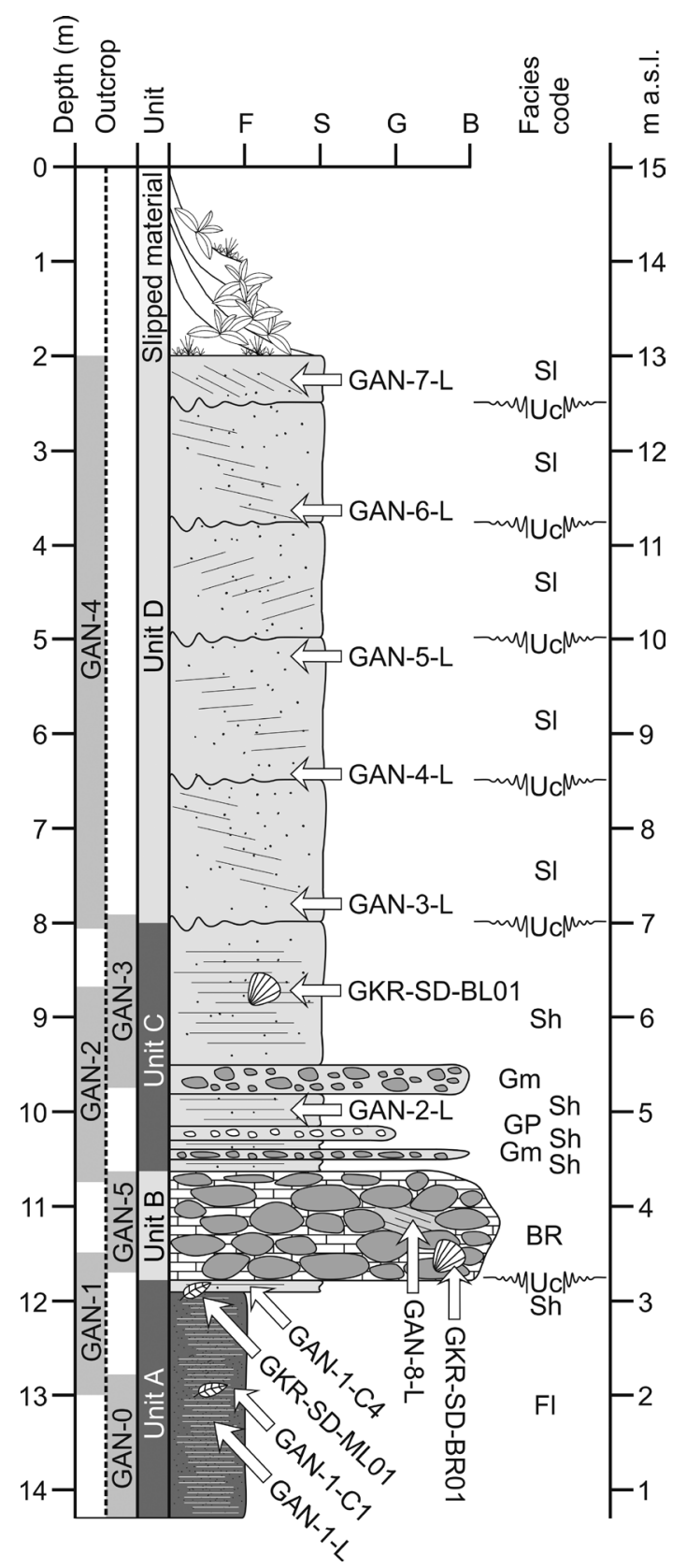

Fig. 10. Synoptic lithostratigraphical profile of the six profiles investigated at the central beach sampling site (location see Fig. 2), comprising mainly unconsolidated sediments. The figure provides the original outcrop correlation (sampling details shown in Fig. 5), major sedimentological units referred to in the text and lithofacies codes modified after Miall (1985). Arrows indicate sampling spots for OSL and radiocarbon dating. Original outcrops and sampling: GAN-0 - dug at the base of the natural outcrop for OSL sampling, but was not sampled for grain size analysis; GAN-1 - basal fine sediments, sampled for grain size analysis and dating; GAN-5 - beach rock section only sampled for dating purposes; GAN-2/3/4 - profiles dug in unconsolidated sediments sampled for dating and grain size analysis. Individual profile logs are provided in Figs. 12 and 13. Lithofacies codes: Fl - laminated fines; Sh - sand horizontally / planar bedded or low angle cross lamination; Sl - sand low angle cross-bedding; $\mathrm{Gm}$ - matrix supported gravel; GP - matrix supported pumice gravel; BR - carbonate cemented gravel and boulders with cemented sand lenses; Uc - unconformity. several layers with high proportions of well-rounded gravels and stones (Fig. 5c). The upper part of the profile continues above an erosional surface and exclusively consists of sands showing clear bedding structures including cross bedding typical for dune sands (Unit D) (Fig. 5f). Based on previous work, these dune sediments consist mainly of well-sorted medium and fine sand ( $>90 \%)$, composed of quartz $(50-60 \%)$, organic aragonite $(30-40 \%)$, and minor contributions rock fragments, and fossil fragments (< $5 \%$ ) (Shih et al. 1994). Feldspar occurrence is rather limited, but evenly distributed. Following the coastline further south (compare Figs. 2 and 4), the fines at the base of the sediment succession thin out and are replaced by the emerging Miocene sandstone. However, despite a reduced thickness, the beach rock layer is still present, now overlying the Miocene rock. At the sampled sediment succession in the central part of the beach (Figs. 5d and 10), the top of the beach rock is exposed at $\sim 4.3 \mathrm{~m}$ a.s.1. In close vicinity of the gully (Fig. 4), it is exposed at $\sim 4.7 \mathrm{~m}$ a.s.l. South of the gully, the beach rock layer is reduced to its minimum thickness directly overlying the Miocene sandstone (Fig. 4e). Here, the beach rock is typically represented by isolated patches of material (Fig. 4e), but these still show a regular alignment of the clasts in original orientation. Towards the southernmost part of the beach, this thin, discontinuous layer of beach rock can be found intermingled with in situ grown coral reef carbonate rocks. In one part of the cliff outcrop (Fig. 4f), a shell-rich layer was identified below the coral reef deposits. It resembles the position of the remnant beach rock and is exposed at around $8 \mathrm{~m}$ a.s.l. in the cliff profile (synoptic profile see Fig. 11).

To better characterize the depositional conditions at the central beach sampling site (Fig. 10), grain size analyses of the unconsolidated fine sediment were conducted. Figure 12 shows the sediment analytical results for Unit A. Figure 13 shows the results for Units C and D, including sediment log, sediment weight percentage, mean grain size, standard deviation of grain size, skewness, kurtosis and carbonate content percentage. The basal Unit A consists of laminated fine sediments rich in plant remains. The grain size composition is typically dominated by silt and clay. However, individual layers may contain higher fractions of sand up to medium sand grain-size. Field mapping showed that such sand-rich layers might often only be several mm thick and such layers occur evenly distributed throughout the unit. No clear coarsening or fining trends were observed. Samples from every $30 \mathrm{~cm}$ were analysed to provide representative results for the grain-size-composition bandwidth present in the outcrop (Fig. 12). Unit A is overlain by the beach-rock (Unit B), which was not analysed with respect to grain-size composition in detail. With the exception of the gravel layers (Fig. 10), the major parts of Units C and D are dominated by sand-sized fractions. The proportions of silt and clay are small, averaging about $10 \%$ at maximum. 
Significant changes in grain size composition can only be observed within the sand fraction. Here, the proportion of very fine sand is also rather constant, whereas major changes can be observed within the coarse, medium, and fine sand fractions. Admixtures of coarse sand are relatively common in Unit C, but only rarely occur in Unit D and are usually connected to the occurrence of unconformities in the profile (Fig. 13). Unit $C$ is characterised by relatively high scatter in mean grain size and standard deviation, which correlates well with the occurrence of gravel layers observed in this unit. Unit D shows a much more homogeneous pattern, but also lacks significant fining or coarsening trends. The skewness and kurtosis values remain rather constant throughout the profile, with the exception of the base of Unit C. Carbonate content also lacks a clear trend and scatters around $15-20 \%$ throughout the profile. The interpretation of these results from grain size analysis will be included in the discussion chapter.

Whereas multiple samples for numerical dating could be obtained from the central beach outcrops, only one layer in the cliff profile (Fig. 11) contained suitable material for dating purposes. A shell (SH-MT-01) from a shell-rich layer was radiocarbon dated to 4980 - 4790 Cal BP (Fig. 11, Table 1). The shell-rich layer is associated with the base of the reduced beach rock layer, which is only present in the form of remnant patches of clast accumulations intermingled with reef carbonates in this outcrop. From a stratigraphical point of view, the beach rock layer functions as a roughly horizontal marker and can clearly be followed northward to the outcrops in the central part of Gangkou beach (Fig. 10). There another shell was taken for radiocarbon dating from the base of the beach rock layer (sample GKR-SD-BR01, Fig. 10). It yielded an age of 4520 - 4245 Cal BP. Although the sampling spots for the two samples are located hundreds of meters apart from each other, they can be associated with the same stratigraphical unit: the beach rock. The two samples yield ages, which are in stratigraphical order (keeping in mind that the cliff sample was taken below the base of the beach rock and the central beach sample was taken from within the basal part of the beach rock). Both ages constrain the timing of the initial development of the beach rock layer. Three samples from the fine sediments at the base of the central beach outcrop (Unit A) below the beach rock were also radiocarbon dated (Fig. 10, Table 1). Two samples from plant remains (Fig. 5b) yielded reliable results. The conventional radiocarbon age for the lowermost sample (GAN-1-C1) intersected twice with the calibration curve and yielded two possible ages of either

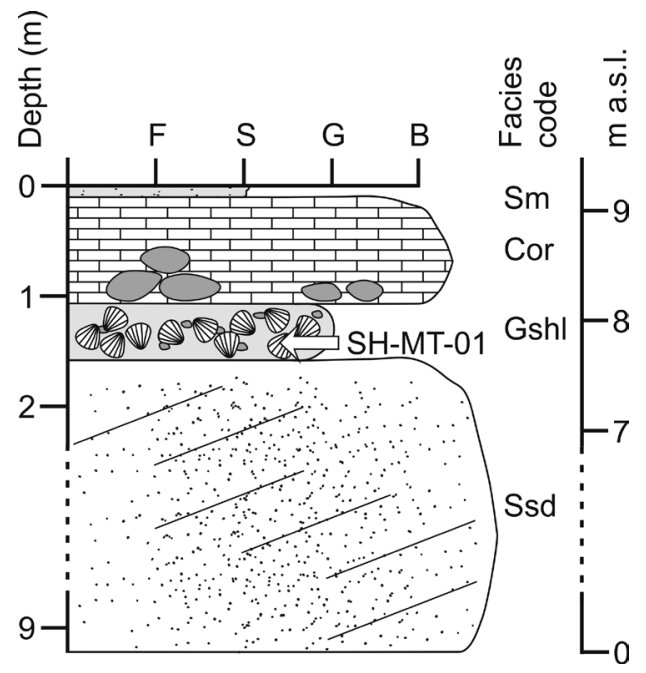

Fig. 11. Synoptic lithostratigraphical profile of the cliff section (location see Fig. 2) showing the succession of a shell-rich layer below coral reef carbonates on top of the Miocene sandstone. Lithofacies codes: Ssd - sandstone; Cor - coral reef carbonates; Gshl - shell debris up to gravel grain-size; $\mathrm{Sm}$ - sand massive.

\section{$\stackrel{\mathrm{F}}{\mathrm{S}} \mathrm{G} \underset{\mathrm{f} m \mathrm{~m}}{\mathrm{~T}} \underset{(\mathrm{m})}{\text { Height }} \quad$ Weight $(\%)$}

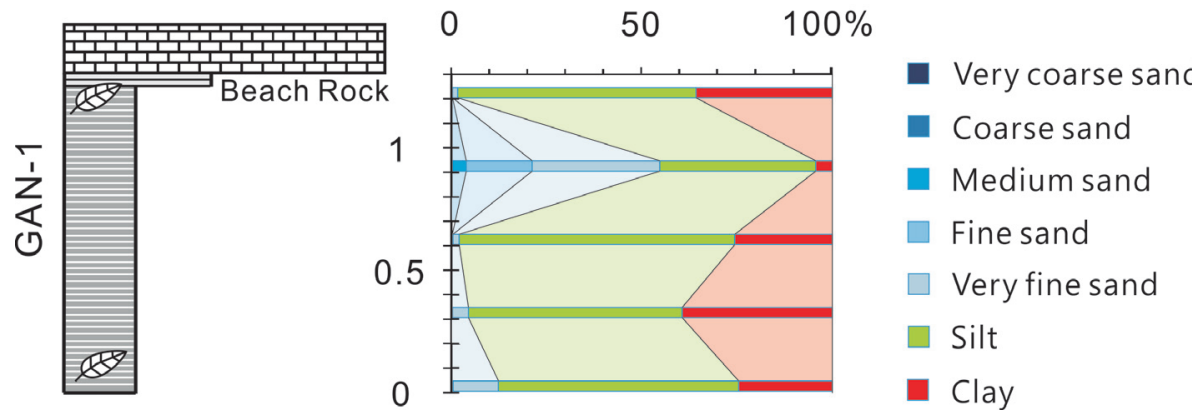

Fig. 12. Grain size results for outcrop GAN-1 (see Fig. 10 for stratigraphical details) determined using a combination of sieving (fraction $>63 \mu$ m), and SediGraph measurements (fraction $<63 \mu \mathrm{m}$ ). Samples were measured every $30 \mathrm{~cm}$ throughout the section, providing representative results for the bandwidth of grain-size-compositions present in the outcrop of laminated silty and clayey sediments containing varying, generally low, percentages of sand. Single sand layers, often only of mm thickness may occur, as is shown by the sample taken at $91 \mathrm{~cm}$. The legend provided here is also valid for Fig. 13. 


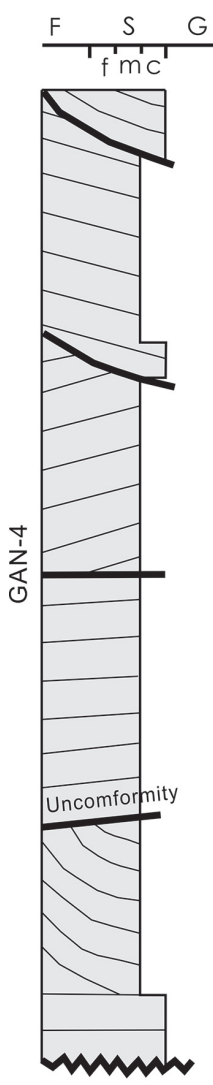
Height Weight (\%) Mz $\quad$ o
$\begin{array}{llll}\sigma & S k_{i} & K_{G}\end{array}$
Carbonate content (\%)
$\begin{array}{llll}0 & 1 & 2 & 3 \Phi\end{array}$
$\begin{array}{llll}10 & 15 \quad 20 \quad 25 \%\end{array}$
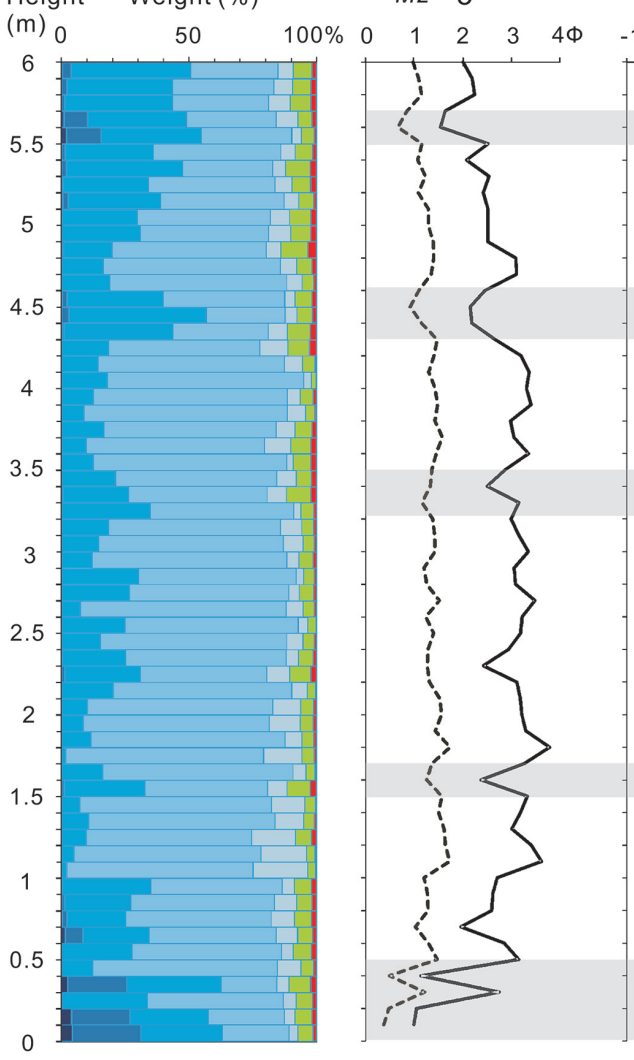

Erosional surface
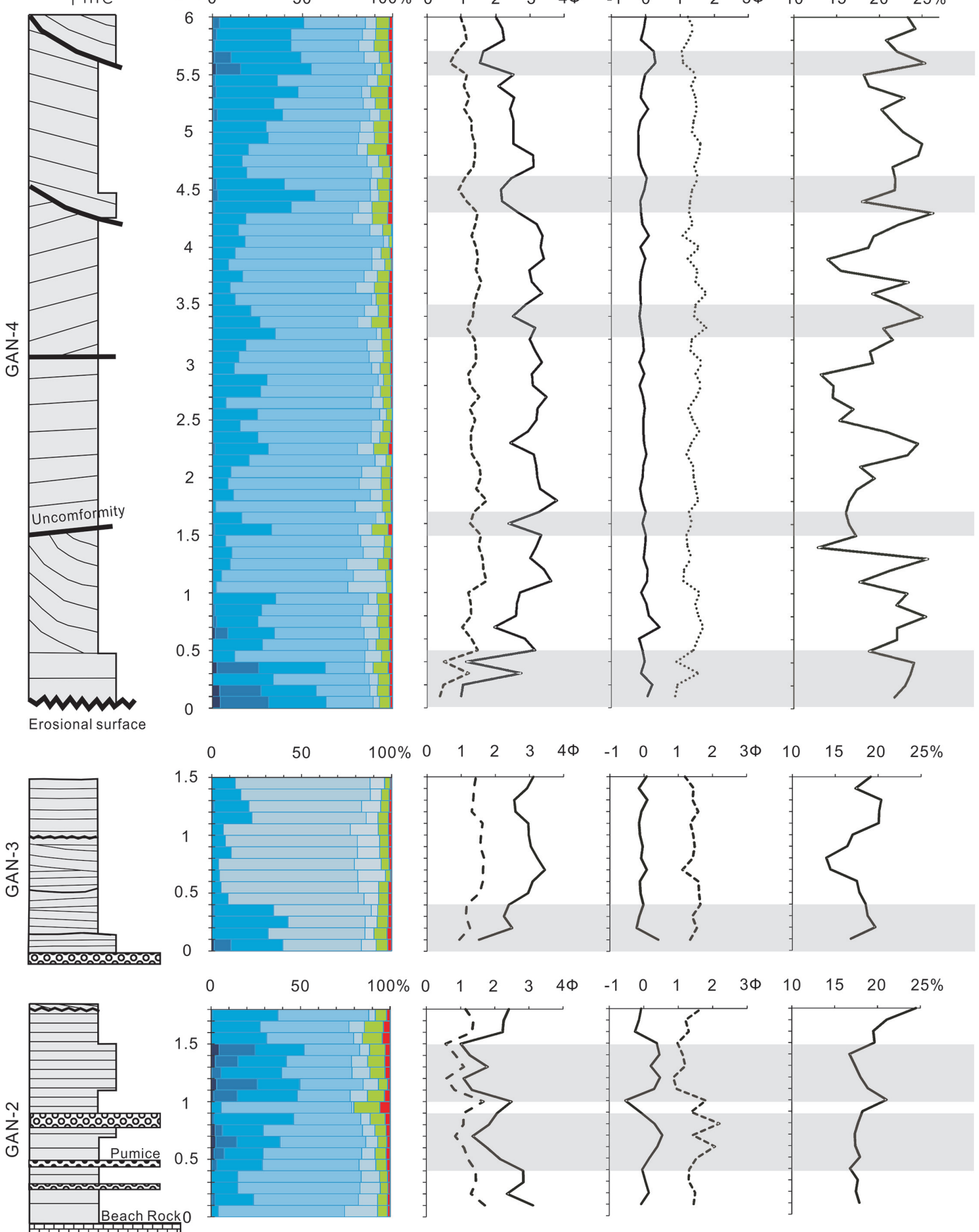

$100 \% \quad 0 \quad 1 \quad 2 \quad 3 \quad 4 \Phi$
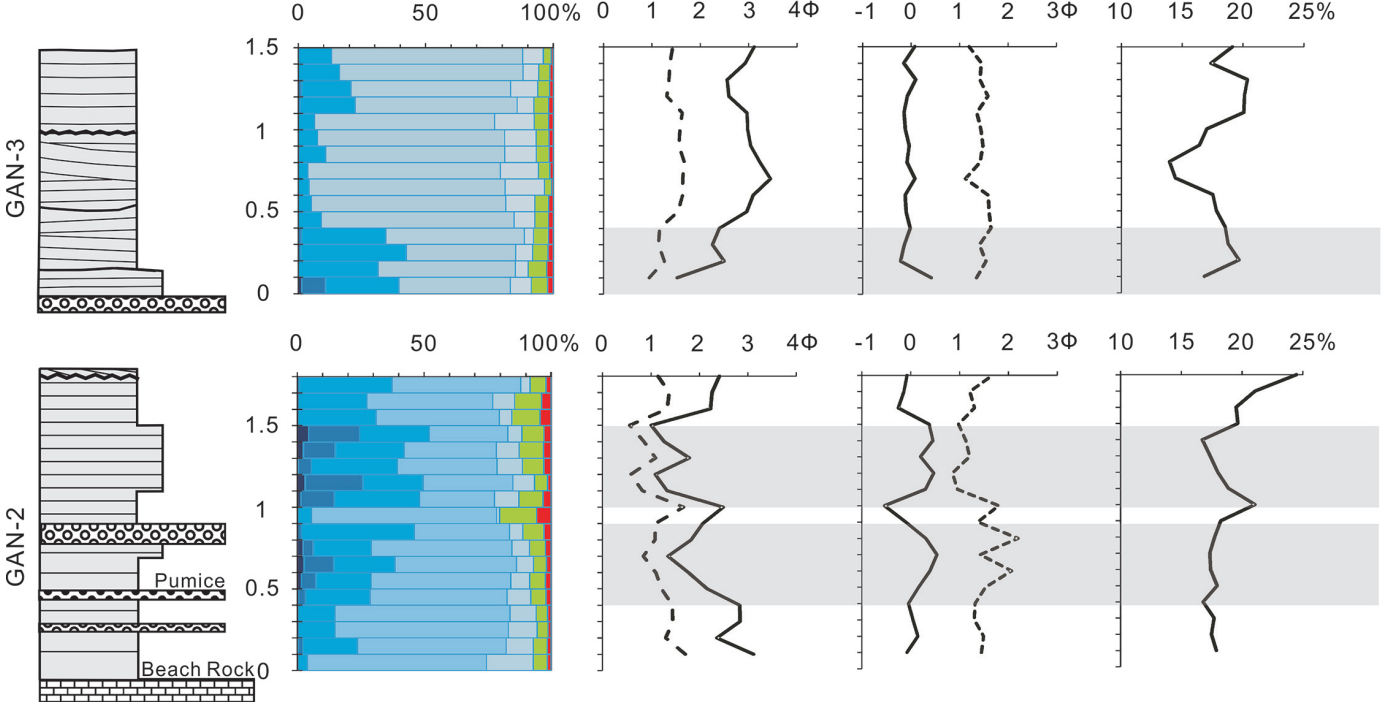

Fig. 13. Grain size results for outcrops GAN-2/3/4 (see Fig. 10 for stratigraphical details). Outcrop GAN-5 comprising the beach rock was not sampled for grain size analysis. Grain size was determined using a Microtrac S3500 laser diffraction particle size analyser. Samples were measured every $10 \mathrm{~cm}$ through the section. The colour-code for the grain-size fractions is provided in Fig. 9. Apart from grain-size related parameters (average grain-size, standard deviation, skewness, and kurtosis), the carbonate content is also provided. 
8155 - 8090 Cal BP or 8055 - 7975 Cal BP. Sample GKRSD-ML01 from right below the beach rock layer was dated to $8005-7935 \mathrm{Cal} \mathrm{BP}$, which is in good agreement with the previous sample. These ages constrain the deposition of fine sediments at the base of the outcrop. An additional sample taken from the middle of the fine sediments (GAN1-C4) did not contain any plant remains, so that the bulk sedimentary carbon was used for dating. The resulting age of 20015 - 19755 Cal BP is clearly overestimating the age range as defined by the two previous samples. A final radiocarbon sample (GKR-SD-BL01) was taken from a shell incorporated into a sand layer of Unit $\mathrm{C}$ and yielded an age of 3430 - 3175 Cal BP. Nine samples from the central beach outcrops were dated using a pIRIR150 luminescence dating approach. Because potassium-rich feldspar is known to suffer from an athermal signal loss over time (anomalous fading; Wintle 1973), fading experiments were conducted for three samples (Table 2). As expected, the g-values determined for the IR50 signal were significantly higher than those determined for the pIRIR150 signal. Including the results from analogue sediments in a nearby sampling site (Ho et al. 2017) to broaden the database, average g-values were calculated for both signals and subsequently used for fading correction: $5.2 \pm 0.5$ for the IR50 signal, and $1.3 \pm 0.3$ for the pIRIR150 signal. One sample (GAN-9) was taken from freshly blown dune sand, which was sampled on the day it was deposited. This sample was used to determine possible residual doses of the IR50 and pIRIR150 signals. While the residual doses calculated for the IR50 signal were negligible as expected, scatter was very high for the pIRIR150 signal (Table 4) and resulted in an apparent age of $0.18 \pm 0.14 \mathrm{ka}$ after fading correction. In summary, the beach sections encompass several thousand years of depositional and paleoenvironmental history, starting with the deposition of the laminated fine sediments at about $8 \mathrm{ka}$, and ending with the deposition of Aeolian sand about 500 years ago.

\section{DISCUSSION}

\subsection{Reliability of Numerical Ages}

The numerical dating results are summarised in Table 1, with radiocarbon dating results and OSL dating results in Table 4. OSL ages based on quartz measurements are available for all fluvial terrace samples (HWA samples). Water-lain sediments are in general prone to incomplete bleaching, leading to age overestimation if not detected and corrected for. The equivalent dose distributions for the HWA luminescence samples indicate that incomplete bleaching is actually present in these samples, but the adopted quartzdating approach is capable of dealing with this issue. All measurements were conducted using small aliquots containing about 80 grains each. Single grain analyses revealed that only about $3 \%$ of the quartz grains emit significant luminescence signals. That means that a maximum of only $2-3$ grains per aliquot contribute to the detected net-OSL signal. Therefore, the measurements are actually close to the single grain level, which minimises the signal averaging effects (Duller 2008). The chosen statistical approach (bootstrapped MAM) used for equivalent dose value calculation for the samples is therefore appropriate and should consequently correct for the effects of incomplete bleaching. In addition, the ages of two samples taken from the higher terrace level $\mathrm{T}_{\mathrm{H}}$ at similar depths (Figs. 3 and 8) agree within the error (Table 4). This can be interpreted as a strong argument for the reliability of the ages with respect to the fact that incomplete bleaching is a random natural process and unlikely to result in identical ages for samples associated with the same geomorphological unit, and therefore with the same depositional event.

All OSL samples from the beach section (Fig. 10) were dated using potassium-rich feldspar as a dosimeter because of the poor luminescence properties of the quartz from coastal sediments (compare Fig. 7). Ho et al. (2017) demonstrated the suitability of K-Fs (potassium-rich feldspar) from the east coast of the Hengchun Peninsula for dating purposes. These results were corroborated, because all OSL ages from the beach profile are in perfect stratigraphic order for both measured K-Fs signals (IR50 and pIRIR150). However, one point deserves to be discussed: The apparent pIRIR150 age of $0.18 \pm 0.14 \mathrm{ka}$ (corrected for fading) determined for the reference sample from recently deposited Aeolian sand (GAN-9-L). Within uncertainty, this may be a significant apparent age, especially for the youngest samples. For all samples, IR50 and pIRIR150 equivalent dose values were calculated using the CAM (Galbraith et al. 1999). Subsequently, ages were calculated for both signals using the software ADELE (Kulig 2005). The resulting ages were then corrected for fading according to the method of Huntley and Lamothe (2001), using the R Luminescence package of Kreutzer et al. (2012). While for all fading corrected ages older than $1 \mathrm{ka}$, the pIRIR150 and the IR50 ages are in good agreement within error, the pIRIR150 ages for the samples younger than 1 ka tend to overestimate the IR50 ages. This might likely be an effect of higher residual doses for the pIRIR150 signal. Although both measured K-Fs signals result in chronologies, which must be regarded as reliable, we decided to choose the pIRIR150 based ages as the most reliable ages for all samples older than $1 \mathrm{ka}$ aiming at minimizing the necessary fading correction. For all samples younger than $1 \mathrm{ka}$, we decided to choose the IR50 based ages as the most reliable ages to minimize the effect of residuals. These ages are printed in bold in Table 4 and will be used for all subsequent interpretation.

In summary, all analysed OSL samples could be reliably dated (Table 4). This is further strengthened when taking the independent age control from radiocarbon dating into account (Table 1). For the beach sections, all OSL ages are in good agreement with the determined radiocarbon ages, with 
two exceptions: Sample GAN-1-C4 gave an age of 20015 19755 Cal BP, which clearly overestimates all other ages. It has to be pointed out that because of the lack of charcoal or plant remains, the bulk carbon content of the sample had to be analysed. The high age likely results from the input of redeposited old carbon into the sediments. That age will be excluded from the chronology and will not be used in all subsequent interpretations. The second exception is sample GKR-SD-BL01 which gave an age of 3430 - 3175 Cal BP. This age must be interpreted as a maximum depositional age because firstly, the shell was not found to be in situ, and secondly, bracketing luminescence ages must be regarded as reliable (Fig. 10, Table 4). Considering the age, the shell was probably eroded from the top of the beach rock and was later redeposited within the beach sediments. This age will also be excluded from the geochronology and will be discarded from all further interpretations. For the radiocarbon ages of the HWA-sections, the situation seems more complex. The radiocarbon ages significantly underestimate the OSL ages. However, based on the reasoning presented above, the quartz OSL ages from the HWA sites must be regarded as reliable. In addition, the radiocarbon samples did not yield distinct ages, because of multiple intersects with the calibration curve. From a geomorphological point of view, the samples taken from the geomorphological unit of the higher terrace level $\mathrm{T}_{\mathrm{H}}$ (HWA-1-C1 and HWA-3-C1) should have yielded ages in agreement within the error, but this is not the case. These facts render the complete radiocarbon dataset from the Hwa-Yuan sites as unreliable. The dated charcoal particles from all three sites were very small (only about several $\mathrm{mm}$ ), so that soil processes may have effectively led to the downward migration of these particles from the surface. Possible processes include intense bioturbation and peloturbation (shrink-swell churning) under the subtropical climatic conditions of the research area (Scharpenseel and BeckerHeidmann 1992; Wilkinson et al. 2009).

\subsection{Paleo-Environmental Reconstruction}

The most comprehensive stratigraphical, sedimentological, and chronological record is the central beach section (Figs. 4, 5, 10, 12, and 13). Because of that, we will start the paleo-environmental reconstruction for that section. Related information gained from the fluvial (Figs. 3, 8) and cliff (Figs. 4, 11) sections will subsequently be correlated and used to expand and refine the paleoenvironmental model summarised in Fig. 14. The eastern coast of the Hengchun Peninsula is classified as a micro tidal environment with a tidal range of approximately $1.9 \mathrm{~m}$ (Yang et al. 2012). According to Dalrymple et al. (1992) estuaries in such micro-tidal environments are generally wave dominated and typically show a tripartite zonation consisting of a seaward marine sand body including a barrier (high energy, wave dominated), a typically muddy central basin (low energy, mixed marine and fluvial energy input), and a bay-head delta (high energy, river dominated). Today's Gangkou River estuary strictly follows this classification. Figure 2 shows the current zonation based on geomorphological mapping. Figure 3 a shows the view from the marine barrier inland towards the Gangkou River estuary wide central basin. The beach section base consists of a succession of $>2 \mathrm{~m}$ of laminated fine sediments, predominantly silt and clay, with few laminations also containing higher proportions of fine to medium sand. Deposition of such small grain sizes transported as suspended load is only possible in low energy zones. In wave dominated estuaries deposition of fine sediment is restricted to sheltered zones beyond the barrier (Oyedotun 2016). Because of that, we interpret the basal sediments of the beach outcrop as central basin deposits from the early Holocene period equivalent to today's Gangkou River estuary. The development of the estuary correlates with the early Holocene sea-level rise (Fig. 14a). The central basin of estuaries is classified as a typical seagrasshabitat (Day et al. 2012). The macrofossils preserved in Unit A of the beach sequence include, among other plant remains, well preserved seagrass leaves (Fig. 5b). The macrofossils are in a good state of preservation, indicating quasi in situ deposition. These facts corroborate the interpretation of Unit A as sediments that were deposited in the central zone of a formerly much wider and further seaward oriented Gangkou River estuary. It came into existence at about $8 \mathrm{ka}$ as determined by OSL and radiocarbon dating (Fig. 14a). This early Holocene estuary likely developed after regression from the maximum flooding surface reconstructed to have occurred between $11-8 \mathrm{ka}$ in the coastal areas of Taiwan (Chen et al. 2004).

The carbonate cemented beach rock layer (Unit B, Fig. 10) discordantly overlies the fine sediments of Unit A. This abrupt change implies a significant alteration in environmental conditions at Gangkou beach. Well-rounded stones and gravel primarily of sandstone lithology dominate the deposits of Unit B. The unit can tentatively be subdivided into layers that are characterized by variations in dominant grain-size, reflecting changes in wave energy level during deposition. The clasts are oriented roughly horizontally following their longitudinal axis. This closely resembles the Gangkou beach surface appearance today (Fig. 3b). The matrix is dominated by coarse to medium sand, with well sorted sand lenses showing cross stratification (Fig. 5d). The top and bottom of the beach rock unit is uniform and straight (Figs. 5a and c). Even if the sediment was uncemented, it would still indicate the change from a central basin estuarine to a wave-dominated beach deposition. Because the research area is situated in a subtropical environment typical for beach rock formation (Vousdoukas et al. 2007), we interpret Unit B as a beach rock. Despite the discussion of whether paleo-sea levels may be derived from beach rock deposits (Hopley 1986; Kelletat 2006; Knight 

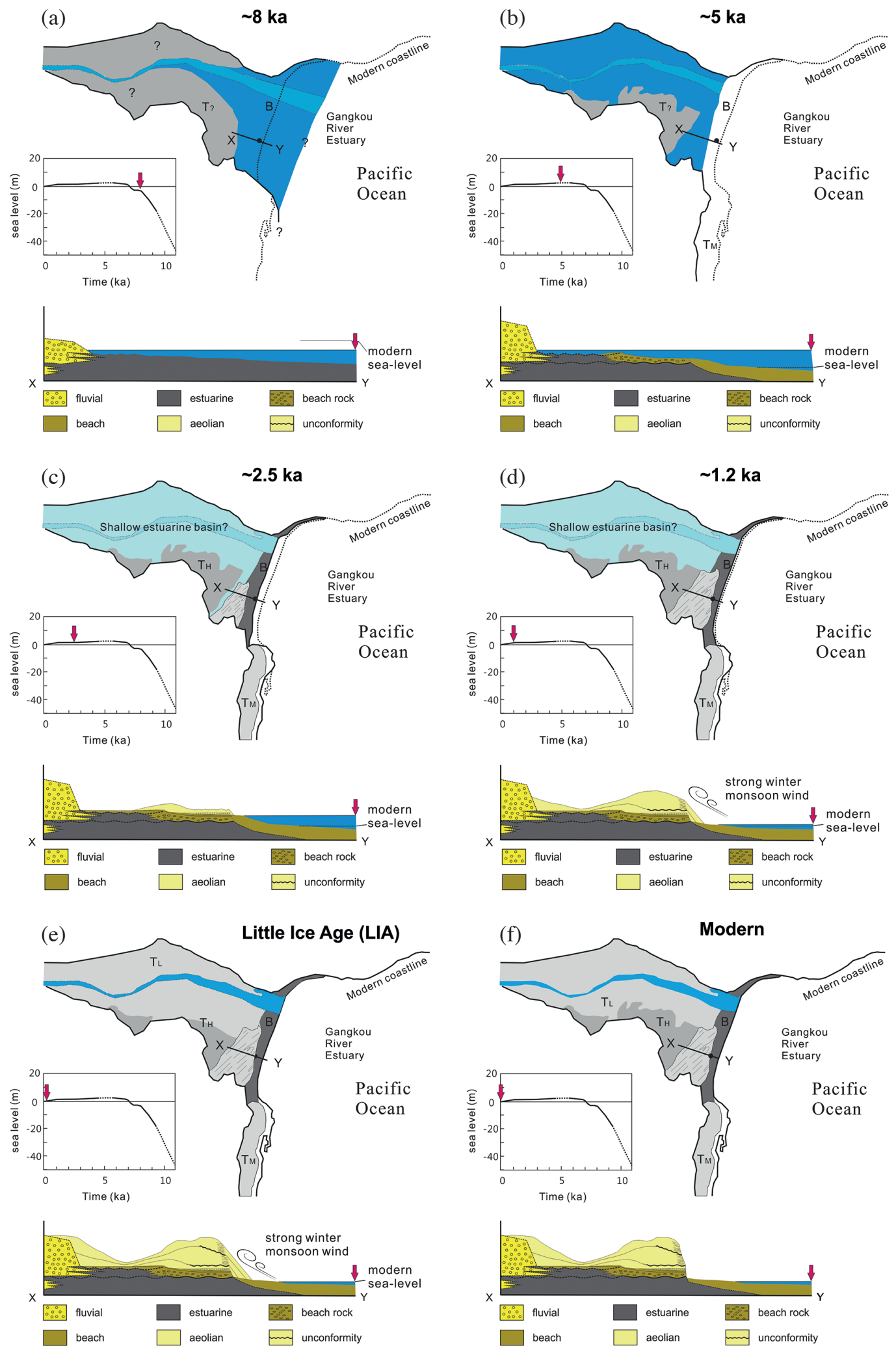

Fig. 14. Evolutionary model of the Gangkou River estuary. For each time slice presented in the subsets (a) - (f), a paleo-map, the respective sea-level at that time, and a sedimentological profile (X - Y) crossing the central beach sampling site is provided. (a) Early Holocene conditions around 8 ka with the Gangkou River estuary starting to develop. (b) Conditions during the Holocene sea-level maximum around 5 ka with an established Gangkou River estuary. (c) Condition at about $2.5 \mathrm{ka}$ with the system adapting to falling sea-level, initiating a transition to a beach environment with initial Aeolian deposition and initial development of fluvial terraces $\left(\mathrm{T}_{\mathrm{H}}\right)$. (d) Conditions around $1.2 \mathrm{ka}$ dominated by Aeolian accumulation and formation of coastal dunes. (e) Little Ice Age (LIA) conditions with continued dune building. Under continuously falling sea-level conditions, fluvial processes lead to the build-up of the $T_{L}$ terrace level even in the former estuarine area. (f) Recent conditions with a confined Gangkou River estuary. 
2007; Vousdoukas et al. 2007), the minimal consensus is that the Unit B deposits were formed in the intertidal zone (Fig. 14b; Vousdoukas et al. 2007). This implies that during its formation, the beach rock was aligned roughly parallel to the paleo-sea level. Therefore, the Unit B deposits play an important role as an originally horizontal marker along the Gangkou beach coastal exposures. The onset of beach development was dated to about $4.5 \mathrm{ka}$ as determined through OSL and radiocarbon dating. This reveals a chronological gap in the sedimentary record (Fig. 10), which spans roughly $3 \mathrm{ka}$ and corresponds to the unconformity between Units A and B. This may be explained by Unit A top fines erosion during the transition from the estuary low energy central zone to a high energy beach environment. This transitional phase can be correlated with a transgressional phase resulting in land ward coastline relocation (Fig. 14b). Towards the south of Gangkou beach, a thinning out of the beach rock layer was observed. In the southernmost part of the research area the remnant, patchy beach rock layer interlocks with coral reef deposits (Fig. 5), which can be explained by the fact that beach rock is known to develop in association with near shore coral reefs (Hopley 1986; Vousdoukas et al. 2007). Such fringing reefs are still typical for southern Taiwan today (Dai 1993). The different basal lithology in the transgressing coastal environment favoured coral growth on the hard rock surface of the Tertiary sandstone, whereas corals could not grow in areas dominated by the estuarine fine sediments. The numerical ages constraining the timing of Unit B beach rock deposition onset perfectly correlates with the Holocene eustatic sea level maximum around 4.7 ka (Chen and Liu 1996; Hsieh and Liew 2010). The beach sediments overlying the fine sediments previously deposited in the former estuary central basin (Fig. 14b), indicate a significant coastline regression of the high energy sand barrier of the wave dominated Gangkou River estuary. This argument is also supported by the data obtained from the overlying Unit $\mathrm{C}$, which is characterized by alternating layers of sand and gravel, including a singular layer containing pumice gravels. The occurrence of such pumice layers in Taiwan is already known, however, dated events of pumice enrichment in coastal environments comprise only the last few hundreds of years. Because of the lack of Holocene volcanism in Taiwan and the geochemical analysis of analysed pumice from two sites, Song et al. (2004) suggested that the origin of such pumice layers could be the arc volcanism of Luzon and the Philippines. From the source areas, the pumice is then transported by the Kuroshio current to areas in the north, including Taiwan. The occurrence of pumice in Unit $\mathrm{C}$ implies that sediment input from southerly direction into the Gangkou beach area seems likely, and it proves the marine, coastal origin of the sediments. In terms of the grain size characteristics of this unit, we interpret the significant changes in mean grain size (Fig. 13) as indicators for changing depositional environments typical for a beach area with alternations of marine, wave deposited beach sediments and Aeolian, wind deposited layers (Figs. 14c and d). Grain size data of profile GAN-2 (Fig. 13) clearly show these alternations: Above the gravel layers in the middle of the profile, the mean grain size decreases from coarse sand $(0.5 \Phi)$ to medium sand $(1 \Phi)$. Below the gravel layer, on the contrary, the mean grain size increases from fine sand $(\sim 1.5 \Phi)$ to medium sand $(1 \Phi)$, which indicates the change in the depositional environment from Aeolian to beach conditions. This pattern continues in profile GAN-3 (Fig. 13) which exposes a $1.5 \mathrm{~m}$-thick layer of fine sediment above a well-rounded gravel layer. The mean grain size decrease from $\sim 1 \Phi$ (median sand) at the bottom $(0-0.5 \mathrm{~m})$ to $\sim 1.5 \Phi$ (fine sand) in the middle of the profile $(0.5-1.1 \mathrm{~m})$, then increases slightly above an erosional surface $(1.1-1.5 \mathrm{~m})$. As shown in Fig. 10, the typical rounded gravel layer and the erosional contact allows correlation of profiles GAN-2 and GAN-3, which show an overlap of about $1 \mathrm{~m}$. While wave processes dominate at the bottom of Unit C, their impact reduces towards the top of the unit, where Aeolian processes prevail. Results from OSL dating provide a time frame for this transitional phase starting latest at $2.55 \pm 0.16 \mathrm{ka}$ (sample GAN-2-L, Fig. 14c) and stopping before $1.25 \pm 0.09 \mathrm{ka}$ (Fig. 14d), with the age of sample GAN-3-L from the bottom of Unit D providing a minimum age for the underlying sediments of Unit $\mathrm{C}$. The sedimentary record preserved from that transitional phase is likely incomplete, because of alternating erosion phases and accumulation of either beach or Aeolian material in the highly dynamic fore- and backshore environment (see unconformities in Fig. 10). Considering the timing, this unit falls into a phase of regression from the eustatic sea level maximum resulting in an extension of beaches in the area (Ho et al. 2017). In their study of the Shuangsi river estuary at Fulong beach (northeastern Taiwan) Dörschner et al. (2012) also identified a transition phase from marine to terrestrial environmental conditions. They dated that phase to about $3 \mathrm{ka}$, which is in good agreement with our findings.

Finally, the sediments of Unit D (Fig. 10) show good sorting with respect to grain size in a fraction and to a degree, which can clearly be associated with Aeolian processes (GAN-4, Fig. 13). Mean grain size of the sediment is mainly medium sand $(\sim 1 \Phi)$, but increases in grain size can be observed whenever unconformities occur in the profile. The occurrence of the four identified unconformities can be interpreted as phases of increased wind speeds, resulting in erosion of old Aeolian sediment. When the wind eases after such erosional phases, sedimentation sets in again. Therefore, the mean grain size above an unconformity usually quickly decreases in an upward direction (Fig. 10). Apart from the coarser fractions present at the base of Unit D, grain size data indicate a slight coarsening upward trend throughout the unit, probably implying an increase in wind power throughout the time of deposition from $1.25 \pm 0.09$ to 
$0.47 \pm 0.04 \mathrm{ka}$. OSL data suggest three phases of Aeolian accumulation documented in the unit, with the oldest initial phase at around $\sim 2.6 \mathrm{ka}$ (strictly speaking still belonging to the transition zone of Unit C), and two dune accumulation phases at about $\sim 1.3 \mathrm{ka}$ and about $\sim 0.6-0.4 \mathrm{ka}$. These phases are in good agreement with the Aeolian accumulation phases detected in the nearby climbing dune at Fung-Chuei-Sha (Ho et al. 2017). Because of limited accessibility, the topmost two meters of the dune could not be sampled. Because the results from OSL dating show rather continuous accumulation without major hiatuses, it is possible to calculate an average accumulation rate for the $6 \mathrm{~m}$ of Aeolian sediment of Unit $\mathrm{D}$. The dating results provide a maximum time frame of $910 \mathrm{a}$, and a minimum time frame of $650 \mathrm{a}$. For $6 \mathrm{~m}$ sediment accumulation this results in a minimum accumulation rate of $\sim 0.7 \mathrm{~cm} \mathrm{a}^{-1}$, and a maximum accumulation rate of $\sim 0.9 \mathrm{~cm} \mathrm{a}^{-1}$. Assuming a constant accumulation rate without significant hiatuses, the top $2 \mathrm{~m}$ of the dune could likely have accumulated in 220 - 290 years. Taking these accumulation rates and the confidence interval of the age for sample GAN-7 into account, Aeolian sand accumulation may have stopped at the site earliest at about 290 a ago and latest at about 140 a ago (Fig. 14e). This is in general agreement with knowledge about coastal dune activity in in the area (Ho et al. 2017), and with the Aeolian record of the Fulong beach area in northeastern Taiwan (Dörschner et al. 2012). A comparison of two sets of aerial photos acquired in two periods from 1977 - 1984 and 2011 - 2012 (Aerial Survey Office of the Forestry Bureau of Taiwan, 1:5,000; http://www.afasi.gov.tw/EN) revealed a generally stable coastline with only minor oscillations caused by coastal erosion and accumulation. This indicates that Gangkou beach has recently been in a metastable state (Fig. 14f).

The importance of the cliff section at the southern end of Gangkou beach (Figs. 2 and 11) lies in the fact that it provides evidence for the fact that the development reconstructed from the beach sections was not exclusively driven by eustatic sea level changes, but also by tectonic influence. A key indicator is the beach rock, which grades into the corals of a former fringing reef in the cliff section (Fig. 8). Our combined dating approach shows that the beach rock formed parallel to the former sea level some 4 - 5 ka ago (Fig. 14b). Dating of the correlate layers in the beach section and the cliff section clearly support the stratigraphical interpretation of the beach rock as a contemporaneous marker horizon. However, in the beach exposures, the top of the beach rock crops out at about $4.3 \mathrm{~m}$ a.s.1., whereas correlate sediments in the cliff section crop out at $>8 \mathrm{~m}$ a.s.l. today. This is clear evidence for tectonic influence in the research area.

Uplift rates for southern Taiwan were calculated and proposed by various authors and range from $3-4 \mathrm{~mm} \mathrm{a}^{-1}$ throughout the Pleistocene, to $1.8-3.5 \mathrm{~mm} \mathrm{a}^{-1}$ throughout the Holocene. These rates were reconstructed from uplifted marine terraces. The highest uplift rates were calculated for sites in close proximity to the Henchun fault (Cheng and Huang 1975; Hsu 1986; Liew and Lin 1987; Chen and Lee 1990; Wang and Burnett 1990; Chen and Liu 1993). To be able to calculate an uplift rate based on the available age constraints for the reef section, several factors must be taken into consideration: The reef growth documented in the cliff outcrop occurred during the phase of the eustatic sea level maximum around $4.7 \mathrm{ka}$ with a $2.4 \mathrm{~m}$ higher sea level (Chen and Liu 1996). Coral growth in fringing reefs in the broader area of southern Taiwan typically occurs in a depth of about $1 \pm 0.5 \mathrm{~m}$ below sea level (Inoue et al. 2011). Because coral growth and beach rock formation are likely to have been contemporaneous, the timing of coral growth can be derived from the ages confining the phase of beach rock development. Coral growth ended earliest at $6.72 \mathrm{ka}$, and ended latest at about $4.25 \mathrm{ka}$. This interval is based on the minimum and maximum boundaries of the confidence intervals of the bracketing ages determined for samples GAN-8-L (OSL age) and GKR-SD-BR01 (radiocarbon age). This provides the period of $6.72-4.25 \mathrm{ka}$ for the end of coral growth. The top of the corals outcrop at about $9 \mathrm{~m}$ a.s.l. in the cliff profile, which corresponds to $6.1 \mathrm{~m}$ above sea level corrected for eustatic effects and a minimum growth depth of corals at $0.5 \mathrm{~m}$ below sea level. Using the lower age limit of the period of coral growth for the calculation, we obtain a minimum uplift rate of $0.9 \mathrm{~mm} \mathrm{a}^{-1}$ at the cliff site. Using the upper limit of the interval for the calculation results in a maximum uplift rate of $1.4 \mathrm{~mm} \mathrm{a}^{-1}$, respectively. This local uplift rate of $0.9-1.4 \mathrm{~mm} \mathrm{a}^{-1}$ clearly lies below the uplift rates calculated for the Holocene cited above. However, following the argumentation of contemporaneous coral growth and beach rock development, the uplift rates that could be calculated for the beach sections are even smaller. Taking the upper limit of the age determined for the deposition of the beach rock cropping out at $4.3 \mathrm{~m}$ a.s.l. into account (sample GAN-8-L, $4.68 \mathrm{ka}$ ), and using the same correction values as in the above calculation, the maximum uplift rate is only $0.3 \mathrm{~mm} \mathrm{a}^{-1}$. This clearly underestimates those rates calculated in previous studies. Our calculations have to be regarded as rough estimates, because the exact position of the beach rock during its formation in relation to sea level cannot be exactly reconstructed as discussed above. Nevertheless, a clear trend of higher average uplift rates in the southern part of Gangkou beach, and relatively lower average uplift rates in the northern part is evident for the period of the last $\sim 4.5 \mathrm{ka}$. This results in the obvious sediment dipping northward along the Gangkou coastline. Ching et al. (2011) demonstrated, that along the eastern part of the Hengchun Peninsula, the long-term uplift rates as calculated by the studies cited above, are contrasted by a short-term subsiding trend (observation period 2000 - 2008). In a recent study primarily focusing on the Hengchun fault activity, Deffontaines et al. (Fig. 10 therein, 2018) presented data derived from GPS surveys along two E-W transects, with the northern 
one reaching the eastern part of our study area. Their results are in agreement with those of Ching et al. (2011), demonstrating that the lower Gangkou River catchment area is in a stable or slightly subsiding trend. The generally low uplift rates calculated from our data provide evidence for the fact that the inversed trend from uplift to subsidence in the area must have happened after $\sim 4.5 \mathrm{ka}$.

The gully shown in Fig. 4 incised through the unconsolidated sediments down into the Miocene sandstone bedrock, which is highly fractured especially on the northern slopes of the gully. This may be an indicator for tectonic stress impacted on the bedrock, potentially favouring erosional processes and leading to the development of the small gully. At the gully outlet, the beach-rock is locally underlain by breccias and conglomerates (Fig. 15). According to recent tectonic models for the Hengchun Peninsula, no active faults should be present in our study area. During field investigations, no distinct vertical displacement of the top of the Miocene bedrock or the beach-rock layer comparing the northern and southern slopes of the gully was detected. However, we additionally compared the dipping angles of the beach-rock layer from the gully towards the north (beach outcrops) and towards the south (cliff outcrop), using a simplified triangular approach (right-angled triangle with vertical and horizontal distances as side lengths). The resulting average dipping angles are $\sim 0.4^{\circ}$ to the north of the dry valley (distance between dry valley and beach outcrops $\sim 150 \mathrm{~m}$, vertical difference of the top of the beach-rock layer $\sim 1 \mathrm{~m}$ ), and $\sim 0.9^{\circ}$ south of the dry valley (distance between dry valley and cliff outcrops $\sim 200 \mathrm{~m}$, vertical difference of the top of the beachrock layer $\sim 3 \mathrm{~m}$ ). These preliminary findings may provide new input to future studies and advancements of the tectonic models for the Hengchun Peninsula. Nevertheless, the overall small rates of uplift calculated for the research area in general are in good agreement with the reconstructed paleoenvironmental development (Fig. 14), which we interpret to have primarily been driven by eustatic sea level forcing. Throughout sea-level high-stands eustatic sea level changes are likely to have affected areas of the Gangkou River basin nowadays situated upstream of the estuary.

Despite the generally narrow width of the active channel, the river valley in the downstream area is remarkably wide (Fig. 2). This is classically termed a misfit or underfit river. Dury (1964) suggests that this is a strong indicator for the occurrence of significant changes of the forcing factors driving the fluvial development. The downstream area of Gangkou River is characterised by the presence of two fluvial terrace levels that are exemplarily preserved in the HwaYuan area (Figs. 2 and 3). The three investigated profiles show similar patterns of coarse, high-energy deposits overlain by overbank fines. Today, the sites under investigation are located upstream of the upper reaches of the bay-head delta and the geomorphological processes are dominated by fluvial high-energy input. Numerical dating for the three sites was not straight forward, and the radiocarbon ages, which significantly underestimate the depositional age, had to be discarded. However, the OSL ages from the sites must be regarded as reliable, which is supported by geomorphological evidence. The dated outcrops HWA-1 and HWA3 can both be associated with the higher terrace level $\mathrm{T}_{\mathrm{H}}$, and the respective OSL ages for both sites are in excellent agreement: HWA-1-L $2.99 \pm 0.43 \mathrm{ka}$ and HWA-3-L $2.87 \pm$ $0.35 \mathrm{ka}$. The OSL age for the site associated with the lower terrace level $\mathrm{T}_{\mathrm{L}}$ is significantly younger (HWA-2-L 0.46 $\pm 0.09 \mathrm{ka})$. Evidence from the coastal sections shows that the Gangkou River mouth functions according to a wavedominated estuary model in a micro-tidal environment. In the course of coastline changes, the landward estuary zones

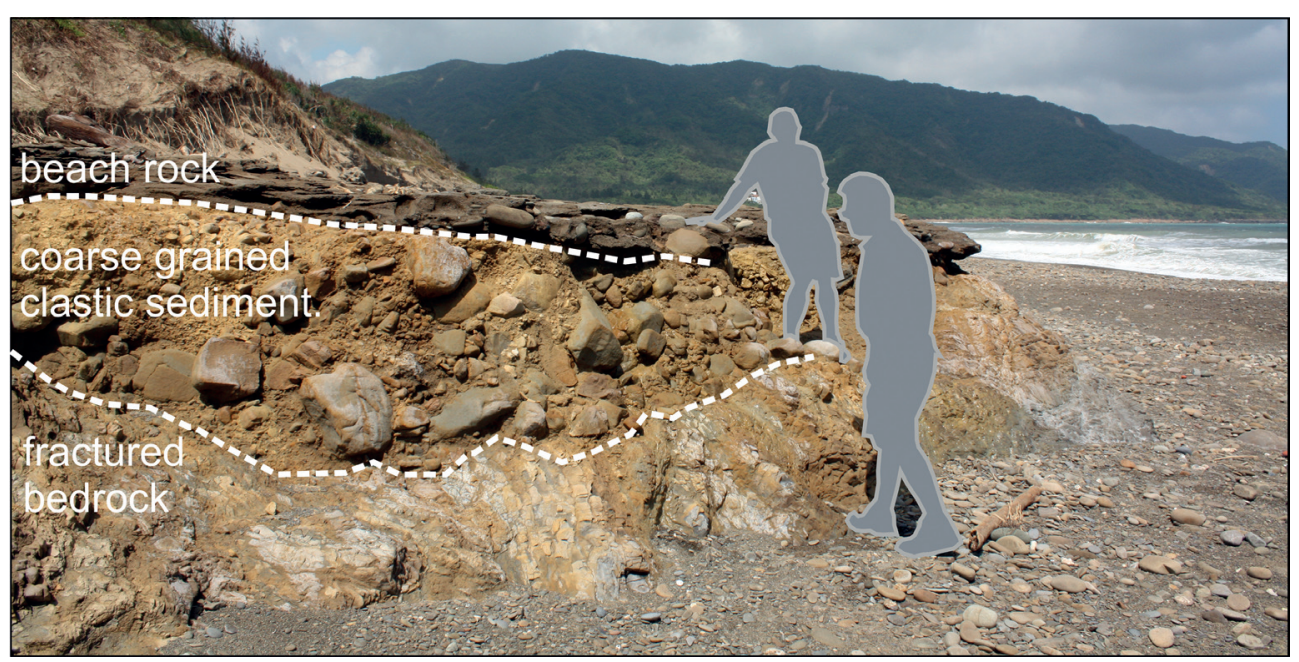

Fig. 15. Photograph of the northern part of the gully outlet. Displayed persons approximately $1.8 \mathrm{~m}$ tall. View to the North towards the Gangkou River outlet. Highly fractured bedrock overlain by cemented, coarse-grained clastic sediments containing varying amounts of angular and rounded pebbles, stones and blocks. The sequence is topped by a thin layer of beach rock. 
also adapted and likely had an effect on the Hwa-Yuan area. Today, the Hwa-Yuan area is situated upstream of the bayhead delta, but throughout the Holocene, it was likely also influenced by the forcing factors identified from the coastal sedimentary archives. One of the major adaption phases of the estuarine development was induced by falling sea level from the Holocene maximum after about $\sim 4.7 \mathrm{ka}$. During that time coastal progradation is documented by a transitional phase from beach to Aeolian deposits in the coastal record which was dated to $2.55 \pm 0.16 \mathrm{ka}$ (Fig. 14c). Within error, this age is in agreement with the terrace ages for sites HWA-1 and HWA-2. The falling sea level and the subsequent seaward displacement of the estuarine zones likely resulted in a shift in the Hwa-Yuan area first to the upper bay-head zone, and finally to the fluvial zone, enabling the aggradation of terrace deposits in the area. This adaption of the estuarine system, which formerly must have reached further upstream, especially during the Holocene sea-level high-stand (Fig. 14b), may have contributed to the Gangkou River underfit. As a side-note, we would like to point out, that according to the out-dated tectonic model for the Hengchun Peninsula, a branch of the Tameihsi/Manchou thrust fault was supposed to have crossed the Hwa-Yuan area. Our results clearly show that there is no evidence for tectonic displacement in the area, which further supports the current tectonic models.

\section{CONCLUSION}

The thorough sedimentological, stratigraphical, and geochronological analysis conducted on the sedimentary archives exposed in the downstream Gangkou River catchment area and Gangkou estuary and beach environment, combined with geomorphological landscape development models of such environments, enabled identifying the major estuarine and coastal evolution forcing factors. Throughout the Holocene period, the landscape development of the wave dominated Gangkou River estuary was primarily driven by changes in the eustatic sea level (Fig. 14). Geochronological and stratigraphical evidence also prove tectonic forcing to be present, but only as a secondary factor.

The reconstructed paleo-environmental history of the Gangkou beach and estuary system, which spans almost the complete Holocene period, documents repeated reactions to disturbances, which challenged the resisting forces of the system. The system was able to recover from these impacts, eventually reaching metastable equilibrium states. However, from our geochronological findings it becomes clear, that the recovery intervals sometimes spanned several thousands of years. The fact that the system was able to recover, shows that another important forcing factor most likely did not change significantly over the observed time interval: The system could not have recovered without sufficient sediment supply. Increasing river regulation measures even in the rather remote Gangkou catchment area are likely to reduce the sedimentary input in the future (Walling 2006). Our findings point towards the direction that the bay-head area of the estuary and the barrier zone receive the sediment input from independent sources. The fluvial terrace sediments of the bay-head area are derived from the catchment itself, while the marine barrier sediments are probably largely independent from the fluvial sediment input from the Gangkou River catchment. When interpreting the diverging luminescence properties of the quartz (Fig. 7) contained in both systems as a provenance indicator (cf. Sawakuchi et al. 2011), it seems likely that the sediment originates from different source areas. Taking the general northward transport direction of sediments by the Kuroshio current into account (documented by the pumice layer in the coastal beach section, Fig. 5e) this seems a plausible scenario.

In summary, the main findings of this study are:

(1) The paleo-environmental reconstruction revealed eustatic sea level change as the primary forcing factor in coastal landscape development in the Gangkou estuarine area, with tectonic forcing only playing a secondary role.

(2) Average uplift rates calculated for the past $\sim 4.5 \mathrm{ka}$ were significantly lower than those calculated by previous studies, most likely indicating that the overall uplifting trend in the research area was recently reverted to a subsiding trend.

(3) Non-uniform uplift caused a tilting of the beach rock exposed at Gangkou beach towards the north.

(4) The reconstructed dune development is in accordance with regional and over regional coastal Aeolian records in Taiwan.

Coastal systems primarily driven by eustatic sea level changes are likely to face significant disturbances in the near future by the projected sea level rise caused by global climate change. Quantifying and analysing possible effects of human activities during the recent past (e.g., land-use changes, flood-risk engineering) on factors like sediment supply and possible resulting alterations on the resilience and vulnerability of such systems should closely be investigated in future studies.

Acknowledgements The authors would like to thank YiChia Wong for valuable assistance during fieldwork. Thanks to Michael Wagreich of the Sedimentology and Stratigraphy group of the University of Vienna and the laboratory staff, namely Maria Meszar and Sabine Hruby-Nichtenberger, for making the SediGraph measurements possible at short notice. The BOKU Vienna Open Access Publishing Fund supported the publication of this study.

\section{REFERENCES}

Adamiec, G. and M. J. Aitken, 1998: Dose-rate conversion factors: Update. Ancient $T L, \mathbf{1 6}, 37-50$. 
Auclair, M., M. Lamothe, and S. Huot, 2003: Measurement of anomalous fading for feldspar IRSL using SAR. Radiat. Meas., 37, 487-492, doi: 10.1016/S13504487(03)00018-0. [Link]

Bailey, R. M. and L. J. Arnold, 2006: Statistical modelling of single grain quartz De distributions and an assessment of procedures for estimating burial dose. Quat. Sci. Rev., 25, 2475-2502, doi: 10.1016/j.quascirev.2005.09.012. [Link]

Banerjee, D., A. S. Murray, L. Bøtter-Jensen, and A. Lang, 2001: Equivalent dose estimation using a single aliquot of polymineral fine grains. Radiat. Meas., 33, 73-94, doi: 10.1016/S1350-4487(00)00101-3. [Link]

Barrier, E. and J. Angelier, 1986: Active collision in eastern Taiwan: The Coastal Range. Tectonophysics, 125, 3972, doi: 10.1016/0040-1951(86)90006-5. [Link]

Bøtter-Jensen, L., E. Bulur, G. A. T. Duller, and A. S. Murray, 2000: Advances in luminescence instrument systems. Radiat.Meas., 32, 523-528, doi: 10.1016/S13504487(00)00039-1. [Link]

Bøtter-Jensen, L., C. E. Andersen, G. A. T. Duller, and A. S. Murray, 2003: Developments in radiation, stimulation and observation facilities in luminescence measurements. Radiat. Meas., 37, 535-541, doi: 10.1016/ S1350-4487(03)00020-9. [Link]

Brunsden, D., 2001: A critical assessment of the sensitivity concept in geomorphology. Catena, 42, 99-123, doi: 10.1016/S0341-8162(00)00134-X. [Link]

Brunsden, D. and J. B. Thornes, 1979: Landscape sensitivity and change. Trans. Inst. Br. Geogr., 4, 463-484, doi: 10.2307/622210. [Link]

Byrne, T. B. and C. S. Liu, 2002: Preface: Introduction to the geology and geophysics of Taiwan. Geology and Geophysics of an Arc-Continent Collision, Taiwan, Geological Society of America, Special Paper 358, Boulder.

Carnero-Bravo, V., J. A. Sanchez-Cabeza, A. C. RuizFernández, M. Merino-Ibarra, J. A. Corcho-Alvarado, H. Sahli, J.-F. Hélie, M. Preda, J. Zavala-Hidalgo, M. Díaz-Asencio, and C. Hillaire-Marcel, 2018: Sea level rise sedimentary record and organic carbon fluxes in a low-lying tropical coastal ecosystem. CATENA, 162, 421-430, doi: 10.1016/j.catena.2017.09.016. [Link]

Carson, M., A. Köhl, D. Stammer, A. B. A. Slangen, C. A. Katsman, R. S. W. van de Wal, J. Church, and N. White, 2016: Coastal sea level changes, observed and projected during the 20th and 21st century. Clim. Change, 134, 269-281, doi: 10.1007/s10584-015-1520-1. [Link]

Chang, C.-P., J. Angelier, T. Q. Lee, and C. Y. Huang, 2003: From continental margin extension to collision orogen: Structural development and tectonic rotation of the Hengchun Peninsula, southern Taiwan. Tectonophysics, 361, 61-82, doi: 10.1016/S0040-1951(02)00561-9. [Link]

Chang, C.-T., M. A. Vadeboncoeur, and T.-C. Lin, 2018:
Resistance and resilience of social-ecological systems to recurrent typhoon disturbance on a subtropical island: Taiwan. Ecosphere, 9, e02071, doi: 10.1002/ ecs2.2071. [Link]

Chen, N., G. Han, and J. Yang, 2018: Mean relative sea level rise along the coasts of the China Seas from mid20th to 21st centuries. Cont. Shelf Res., 152, 27-34, doi: 10.1016/j.csr.2017.12.002. [Link]

Chen, Y.-G. and T.-K. Liu, 1993: Holocene radiocarbon dates in Hengchun Peninsula and their neotectonic implications. J. Geol. Soc. China, 36, 457-479.

Chen, Y.-G. and T.-K. Liu, 1996: Sea Level Changes in the Last Several Thousand Years, Penghu Islands, Taiwan Strait. Quat. Res., 45, 254-262, doi: 10.1006/ qres.1996.0026. [Link]

Chen, W. S., 2016: Introduction to the geology of Taiwan. Geological Society of Taiwan, Taipei, 204 pp.

Chen, W. S. and W. C. Lee, 1990: Reconsideration of the stratigraphy of the western Hengchun Hill. Ti-Chih, 10, 127-140.

Chen, W. S., S. H. Sung, L. C. Wu, H. D. Hsu, and H. C. Yang, 2004: Shoreline changes in the coastal plain of Taiwan since the last glacial epoch. Bulletin of the Department of Anthropology, 62, 40-55. (in Chinese)

Cheng, Y. M. and C. Y. Huang, 1975: Biostratigraphic study in the west Hengchun hill. Acta Geol. Taiwan., 18, 49-59.

Ching, K. E., M. L. Hsieh, K. M. Johnson, K. H. Chen, R. J. Rau, and M. Yang, 2011: Modern vertical deformation rates and mountain building in Taiwan from precise leveling and continuous GPS observations, 2000-2008. J. Geophys. Res., 116, doi: 10.1029/2011JB008242. [Link]

Courchamp, F., B. D. Hoffmann, J. C. Russell, C. Leclerc, and C. Bellard, 2014: Climate change, sea-level rise, and conservation: Keeping island biodiversity afloat. Trends Ecol. Evol., 29, 127-130, doi: 10.1016/j. tree.2014.01.001. [Link]

Cunningham, A. C. and J. Wallinga, 2010: Selection of integration time intervals for quartz OSL decay curves. Quaternary Geochronology, 5, 657-666, doi: 10.1016/j. quageo.2010.08.004. [Link]

Cunningham, A. C. and J. Wallinga, 2012: Realizing the potential of fluvial archives using robust OSL chronologies. Quaternary Geochronology, 12, 98-106, doi: 10.1016/j.quageo.2012.05.007. [Link]

Dadson, S. J., N. Hovius, H. Chen, W. B. Dade, M.-L. Hsieh, S. D. Willett, J.-C. Hu, M.-J. Horng, M.-C. Chen, C. P. Stark, D. Lague, and J.-C. Lin, 2003: Links between erosion, runoff variability and seismicity in the Taiwan orogen. Nature, 426, 648-651, doi: 10.1038/nature02150. [Link]

Dai, C. F., 1993: Patterns of Coral Distribution and Benthic Space Partitioning on the Fringing Reefs of Southern 
Taiwan. Marine Ecology, 14, 185-204, doi: 10.1111/ j.1439-0485.1993.tb00479.x. [Link]

Dalrymple, R. W., B. A. Zaitlin, and R. Boyd, 1992: Estuarine facies models; conceptual basis and stratigraphic implications. J. Sediment. Res., 62, 1130-1146, doi: 10.1306/ d4267a69-2b26-11d7-8648000102c1865d. [Link]

Day, J. W., A. Yáñez-Arancibia, W. M. Kemp, and B. C. Crump, 2012: Introduction to estuarine Ecology. In: Day, J. W., B. C. Crump, W. M. Kemp, and A. YáñezArancibia (Eds.), Estuarine Ecology, Wiley-Blackwell, 1-18, doi: 10.1002/9781118412787.ch1. [Link]

Deffontaines, B., K.-J. Chang, J. Champenois, K.-C. Lin, C.T. Lee, R.-F. Chen, J.-C. Hu, and S. Magalhaes, 2018: Active tectonics of the onshore Hengchun Fault using UAS DSM combined with ALOS PS-InSAR time series (Southern Taiwan). Nat. Hazards Earth Syst. Sci., 18, 829-845, doi: 10.5194/nhess-18-829-2018. [Link]

Dörschner, N., T. Reimann, D. Wenske, C. Lüthgens, S. Tsukamoto, M. Frechen, and M. Böse, 2012: Reconstruction of the Holocene coastal development at Fulong Beach in north-eastern Taiwan using optically stimulated luminescence (OSL) dating. Quat. Int., 263, 3-13, doi: 10.1016/j.quaint.2011.12.009. [Link]

Duller, G. A.T., 2008: Single-grain optical dating of Quaternary sediments: Why aliquot size matters in luminescence dating. Boreas, 37, 589-612, doi: 10.1111/j.15023885.2008.00051.x. [Link]

Dury, G. H., 1964: Principles of underfit streams. Professional Paper 452-A, US Government Printing Office, A1-A67.

Feagin, R. A., D. J. Sherman, and W. E. Grant, 2005: Coastal erosion, global sea-level rise, and the loss of sand dune plant habitats. Front. Ecol. Environ., 3, 359-364, doi: 10.1890/1540-9295(2005)003[0359:CEGSRA]2. 0.CO;2. [Link]

Galbraith, R. F., R. G. Roberts, G. M. Laslett, H. Yoshida, and J. M. Olley, 1999: Optical dating of single and multiple grains of Quartz from Jinmium rock shelter, northern Australia: Part I, experimental design and statistical models. Archaeometry, 41, 339-364, doi: 10.1111/j.1475-4754.1999.tb00987.x. [Link]

Giletycz, S., N. Loget, C.-P. Chang, and F. Mouthereau, 2015: Transient fluvial landscape and preservation of low-relief terrains in an emerging orogen: Example from Hengchun Peninsula, Taiwan. Geomorphology, 231, 169-181, doi: 10.1016/j.geomorph.2014.11.026. [Link]

Ho, L. D., C. Lüthgens, Y. C. Wong, J. Y. Yen, and S. J. Chyi, 2017: Late Holocene cliff-top dune evolution in the Hengchun Peninsula of Taiwan: Implications for palaeoenvironmental reconstruction. J. Asian Earth Sci., 148, 13-30, doi: 10.1016/j.jseaes.2017.08.024. [Link]

Hopley, D., 1986: Beachrock as a sea-level indicator. In: Van de Plassche, O. (Ed.), Sea-Level Research: A Manual for the Collection and Evaluation of Data,
Springer, Dordrecht, 157-173, doi: 10.1007/978-94009-4215-8_6. [Link]

Hsieh, M. L. and P. M. Liew, 2010: A New Version of Holocene Tectonic Uplift Rates along the Hua-Tung Coast of Eastern Taiwan. Bulletin of the Central Geological Survey, 23, 165-200. (in Chinese)

Hsu, C. M., 1986: Late Quaternary tectonics of the Hengchun Peninsula, southern Taiwan. Ph.D. Thesis, National Taiwan University, Taiwan. (Unpublished)

Huang, C.-Y., 1988: Foraminiferal paleoecology of a Late Pleistocene lagoonal sequence of the Szekou Formation in the Hengchun Peninsula, southern Taiwan. Proc. Geol. Soc. China, 31, 181-206.

Huang, C.-Y., Y. Yen, Q. Zhao, and C.-T. Lin, 2012: Cenozoic stratigraphy of Taiwan: Window into rifting, stratigraphy and paleoceanography of South China Sea. Chin. Sci. Bull., 57, 3130-3149, doi: 10.1007/s11434012-5349-y. [Link]

Huntley, D. J. and M. R. Baril, 1997: The K content of the $\mathrm{K}$-feldspars being measured in optical dating or in thermoluminescence dating. Ancient TL, 15, 11-13.

Huntley, D. J. and M. Lamothe, 2001: Ubiquity of anomalous fading in $\mathrm{K}$-feldspars and the measurement and correction for it in optical dating. Can. J. Earth Sci., 38, 1093-1106, doi: 10.1139/e01-013. [Link]

Inoue, S., H. Kayanne, N. Matta, W. S. Chen, and Y. Ikeda, 2011: Holocene uplifted coral reefs in Lanyu and Lutao Islands to the southeast of Taiwan. Coral Reefs, 30, 581-592, doi: 10.1007/s00338-011-0783-x. [Link]

IPCC, 2014: Climate Change 2014: Synthesis Report. Contribution of Working Groups I, II and III to the Fifth Assessment Report of the Intergovernmental Panel on Climate Change, IPCC, Geneva, Switzerland, $151 \mathrm{pp}$.

Kelletat, D., 2006: Beachrock as Sea-Level Indicator? Remarks from a Geomorphological Point of View. $J$. Coast. Res., 22, 1558-1564, doi: 10.2112/04-0328.1. [Link]

Knight, J., 2007: Beachrock Reconsidered. Discussion of: Kelletat, D., 2006. Beachrock as Sea-Level Indicator? Remarks from a Geomorphological Point of View. Journal of Coastal Research, 22(6), 1558-1564. J. Coast. Res., 23, 1074-1078, doi: 10.2112/07-0836.1. [Link]

Kreutzer, S., C. Schmidt, M. C. Fuchs, M. Dietze, M. Fischer, and M. Fuchs, 2012: Introducing an R package for luminescence dating analysis. Ancient $T L, \mathbf{3 0}, 1-8$.

Kulig, G., 2005: Erstellung einer Auswertesoftware zur Altersbestimmung mittels Lumineszenz-verfahren unter spezieller Berücksichtigung des Einflusses radioaktiver Ungleichgewichte in der ${ }^{238} \mathrm{U}$-Zerfallsreihe. B.Sc. Thesis, Technische Universität Bergakademie Freiberg, Freiberg.

Lewis, D. W. and D. McConchie, 1994: Analytical Sedimentology, Springer US, 197 pp, doi: 10.1007/978-14615-2636-0. [Link] 
Liew, P. M. and C. F. Lin, 1987: Holocene tectonic activity of the Hengchun Peninsula as evidenced by the deformation of marine terraces. Mem. Geol. Soc. China, 9 , 241-259.

Lüthgens, C., M. Böse, and F. Preusser, 2011: Age of the Pomeranian ice-marginal position in northeastern Germany determined by Optically Stimulated Luminescence (OSL) dating of glaciofluvial sediments. Boreas, 40, 598-615, doi: 10.1111/j.1502-3885.2011.00211.x. [Link]

Lüthgens, C., S. Neuhuber, S. Grupe, T. Payer, M. Peresson, and M. Fiebig, 2017: Geochronological investigations using a combination of luminescence and cosmogenic nuclide burial dating of drill cores from the Vienna Basin. Zeitschrift der Deutschen Gesellschaft für Geowissenschaften, 168, 115-140, doi: 10.1127/ zdgg/2017/0081. [Link]

Mejdahl, V., 1979: Thermoluminescence dating: Beta-dose attenuation in quartz grains. Archaeometry, 21, 61-72, doi: 10.1111/j.1475-4754.1979.tb00241.x. [Link]

Mesalles, L., F. Mouthereau, M. Bernet, C.-P. Chang, A. T.-S. Lin, C. Fillon, and X. Sengelen, 2014: From submarine continental accretion to arc-continent orogenic evolution: The thermal record in southern Taiwan. Geology, 42, 907-910, doi: 10.1130/G35854.1. [Link]

Miall, A. D., 1985: Architectural-element analysis: A new method of facies analysis applied to fluvial deposits. Earth-Sci. Rev., 22, 261-308, doi: 10.1016/00128252(85)90001-7. [Link]

Murray, A. S. and A. G. Wintle, 2000: Luminescence dating of quartz using an improved single-aliquot regenerative-dose protocol. Radiat. Meas., 32, 57-73, doi: 10.1016/S1350-4487(99)00253-X. [Link]

Murray, A. S. and A. G. Wintle, 2003: The single aliquot regenerative dose protocol: potential for improvements in reliability. Radiat. Meas., 37, 377-381, doi: 10.1016/ S1350-4487(03)00053-2. [Link]

Nicholls, R. J. and A. Cazenave, 2010: Sea-Level Rise and Its Impact on Coastal Zones. Science, 328, 1517-1520, doi: 10.1126/science.1185782. [Link]

Nováčková, M. and R. S. J.Tol, 2018: Effects of sea level rise on economy of the United States. J.Environ. Econ.Policy, 7, 85-115, doi: 10.1080/21606544.2017.1363667. [Link]

Oyedotun, T. D. T., 2016: Sediment Characterisation in an Estuary-Beach System. J. Coast. Zone Manag., 19, doi: 10.4172/2473-3350.1000433. [Link]

Pelletier, B. and J. F. Stephan, 1986: Middle Miocene deduction and late Miocene beginning of collision registered in the hengchun peninsula: Geodynamic implications for the evolution of Taiwan. Tectonophysics, 125, 133-160, doi: 10.1016/0040-1951(86)90011-9. [Link]

Pethick, J. S. and S. Crooks, 2000: Development of a coastal vulnerability index: a geomorphological perspec- tive. Environ. Conservat., 27, 359-367, doi: 10.1017/ S0376892900000412. [Link]

Prescott, J. R. and J. T. Hutton, 1994: Cosmic ray contributions to dose rates for luminescence and ESR dating: Large depths and long-term time variations. Radiat. Meas.,23,497-500, doi: 10.1016/1350-4487(94)900868. [Link]

Prescott, J. R. and L. G. Stephan, 1982: The contribution of cosmic radiation to the environmental dose for thermoluminescence dating: Latitude, altitude and depth dependencies. PACT Brussels, 6, 17-25.

Preusser, F., D. Degering, M. Fuchs, A. Hilgers, A. Kadereit, N. Klasen, M. Krbetschek, D. Richter, and J. Q. G. Spencer, 2008: Luminescence dating: Basics, methods and applications. E\&G Quaternary Sci.J., 57, 95-149, doi: 10.3285/eg.57.1-2.5. [Link]

Rades, E. F., M. Fiebig, and C. Lüthgens, 2018: Luminescence dating of the Rissian type section in southern Germany as a base for correlation. Quat. Int., 478, 3850, doi: 10.1016/j.quaint.2016.07.055. [Link]

Ramsey, L. A., N. Hovius, D. Lague, and C. S. Liu, 2006: Topographic characteristics of the submarine Taiwan orogen. J. Geophys. Res., 111, 1-21, doi: 10.1029/2005JF000314. [Link]

Reimann, T. and S. Tsukamoto, 2012: Dating the recent past ( $<500$ years) by post-IR IRSL feldspar - Examples from the North Sea and Baltic Sea coast. Quaternary Geochronology, 10, 180-187, doi: 10.1016/j. quageo.2012.04.011. [Link]

Rhodes, E. J., 2011: Optically stimulated luminescence dating of sediments over the past 200,000 years. Аnnu. Rev. Earth Planet. Sci., 39, 461-488, doi: 10.1146/ annurev-earth-040610-133425. [Link]

Roberts, H. M., 2007: Assessing the effectiveness of the double-SAR protocol in isolating a luminescence signal dominated by quartz. Radiat. Meas., 42, 16271636, doi: 10.1016/j.radmeas.2007.09.010. [Link]

Sawakuchi, A. O., M. W. Blair, R. DeWitt, F. M. Faleiros, T. Hyppolito, and C. C. F. Guedes, 2011: Thermal history versus sedimentary history: OSL sensitivity of quartz grains extracted from rocks and sediments. Quaternary Geochronology, 6, 261-272, doi: 10.1016/j.quageo.2010.11.002. [Link]

Scharpenseel, H. W. and P. Becker-Heidmann, 1992: Twenty-Five Years of Radiocarbon Dating Soils: Paradigm of Erring and Learning. Radiocarbon, 34, 541-549, doi: 10.1017/s0033822200063803. [Link]

Shih, T. T., J. C. Chang, C. L. Chang, C. C. Lien, and H. M. Lin, 1994: A geomorphological study of sand dunes in southern and eastern coast of Taiwan. Geogr. Res., 21, 1-42. (in Chinese)

Shyu, J. B. H., K. Sieh, Y.-G. Chen, and C.-S. Liu, 2005: Neotectonic architecture of Taiwan and its implications for future large earthquakes. J. Geophys. Res., 
110, doi: 10.1029/2004JB003251. [Link]

Song, S. R., C. M. Liu, C. H. Chen, and W. Lo, 2004: Pumice layers in marine terraces: Implications for tectonic uplift rates on the east and northeast coasts of Taiwan over the last hundreds of years. Quat. Int., 115-116, 8392, doi: 10.1016/S1040-6182(03)00098-3. [Link]

Sung, Q.-C., 1991: Explanatory text of the geological map of Taiwan. Hengchun Peninsula (Scale 1: 50,000, Sheet numbers: 69, 70, and 72): Taiwan, Central Geological Survey, MOEA, 1-61.

Suppe, J., 1980: Imbricated structure of western foothills belt, southcentral Taiwan. Petrol. Geol. Taiwan, 17, $1-16$.

Suppe, J., 1984: Kinematics of arc-continent collision, flipping of subduction, and back-arc spreading near Taiwan. Mem. Geol. Soc. China, 6, 21-33.

Suroso, D. S. A. and T. Firman, 2018: The role of spatial planning in reducing exposure towards impacts of global sea level rise case study: Northern coast of Java, Indonesia. Ocean Coast. Manag., 153, 84-97, doi: 10.1016/j.ocecoaman.2017.12.007. [Link]

Teng, L. S., 1990: Geotectonic evolution of late Cenozoic arc-continent collision in Taiwan. Tectonophysics, 183, 57-76, doi: 10.1016/0040-1951(90)90188-E. [Link]

Thomsen, K. J., L. Bøtter-Jensen, P. M. Denby, P. Moska, and A. S. Murray, 2006: Developments in luminescence measurement techniques. Radiat. Meas., 41, 768-773, doi: 10.1016/j.radmeas.2006.06.010. [Link]

Tseng, C.-H., D. Wenske, M. Böse, T. Reimann, C. Lüthgens, and M. Frechen, 2013: Sedimentary features and ages of fluvial terraces and their implications for geomorphic evolution of the Taomi River catchment: A case study in the Puli Basin, central Taiwan. J. Asian Earth Sci., 62, 759-768, doi: 10.1016/j.jseaes.2012.11.028. [Link]

Tseng, C.-H., C. Lüthgens, S. Tsukamoto, T. Reimann, M. Frechen, and M. Böse, 2016: Late Pleistocene to Holocene alluvial tableland formation in an intra-mountainous basin in a tectonically active mountain belt - A case study in the Puli Basin, central Taiwan. Quat. Sci. Rev.,132,26-39, doi: 10.1016/j.quascirev.2015.11.006. [Link]

Vita-Finzi, C. and J.-C. Lin, 2005: Neotectonics and seismic hazard assessment in Hengchun Peninsula, southern Taiwan. C. R. Geosci., 337, 1194-1199, doi: 10.1016/j. crte.2005.04.014. [Link]

Vousdoukas, M. I., A. F. Velegrakis, and T. A. Plomaritis, 2007: Beachrock occurrence, characteristics, formation mechanisms and impacts. Earth-Sci. Rev., 85, 2346, doi: 10.1016/j.earscirev.2007.07.002. [Link]

Wainwright, D. J., R. Ranasinghe, D. P. Callaghan, C. D. Woodroffe, R. Jongejan, A. J. Dougherty, K. Rogers, and P. J. Cowell, 2015: Moving from deterministic towards probabilistic coastal hazard and risk assessment:
Development of a modelling framework and application to Narrabeen Beach, New South Wales, Australia. Coast. Eng., 96, 92-99, doi: 10.1016/j.coastaleng.2014.11.009. [Link]

Walling, D. E., 2006: Human impact on land-ocean sediment transfer by the world's rivers. Geomorphology, 79, 192216, doi: 10.1016/j.geomorph.2006.06.019. [Link]

Wallinga, J., 2002: On the detection of OSL age overestimation using single-aliquot techniques. Geochronometria, 21, 17-26.

Wang, C. H. and W. C. Burnett, 1990: Holocene mean uplift rates across an active plate-collision boundary in Taiwan. Science, 248, 204-206, doi: 10.1126/science. 248.4952.204. [Link]

Wilkinson, M. T., P. J. Richards, and G. S. Humphreys, 2009: Breaking ground: Pedological, geological, and ecological implications of soil bioturbation. Earth-Sci.Rev., 97, 257-272, doi: 10.1016/j.earscirev.2009.09.005. [Link]

Wintle, A. G., 1973: Anomalous Fading of Thermo-luminescence in Mineral Samples. Nature, 245, 143-144, doi: 10.1038/245143a0. [Link]

Wintle, A. G., 2008: Luminescence dating: Where it has been and where it is going. Boreas, 37, 471-482, doi: 10.1111/j.1502-3885.2008.00059.x. [Link]

Wintle, A. G. and A. S. Murray, 2006: A review of quartz optically stimulated luminescence characteristics and their relevance in single-aliquot regeneration dating protocols. Radiat. Meas., 41, 369-391, doi: 10.1016/j. radmeas.2005.11.001. [Link]

Woodroffe, C. D., 2007: The natural resilience of coastal systems: Primary concepts. In: McFadden, L., E. Penning-Rowsell, and R. J. Nicholls (Eds.), Managing Coastal Vulnerability, Elsevier, Amsterdam, 45-60.

Yang, R.-Y., Y.-C. Wu, and H.-H. Hwung, 2012: Beach Erosion Management with the Application of Soft Countermeasure in Taiwan. In: Curkovic, S. (Ed.), Sustainable Development: Authoritative and Leading Edge Content for Environmental Management, IntechOpen, 349-370, doi: 10.5772/45883. [Link]

Yu, S. B., H. Y. Chen, and L. C. Kuo, 1997: Velocity field of GPS stations in the Taiwan area. Tectonophysics, 274, 41-59, doi: 10.1016/S0040-1951(96)00297-1. [Link]

Zhang, X., Y. Yan, C.-Y. Huang, D. Chen, Y. Shan, Q. Lan, W. Chen, and M. Yu, 2014: Provenance analysis of the Miocene accretionary prism of the Hengchun Peninsula, southern Taiwan, and regional geological significance. J. Asian Earth Sci., 85, 26-39, doi: 10.1016/j. jseaes.2014.01.021. [Link]

Zhang, X., P. A. Cawood, C.-Y. Huang, Y. Wang, Y. Yan, M. Santosh, W. Chen, and M. Yu, 2016: From convergent plate margin to arc-continent collision: Formation of the Kenting Mélange, Southern Taiwan. Gondwana Res., 38, 171-182, doi: 10.1016/j.gr.2015.11.010. [Link] 